\title{
A Single Intraventricular Injection of VEGF Leads to Long-Term Neurotrophic Effects in Axotomized Motoneurons
}

\author{
Paula M. Calvo, Rosa R. de la Cruz, and Angel M. Pastor
}

https://doi.org/10.1523/ENEURO.0467-19.2020

Departamento de Fisiología, Facultad de Biología, Universidad de Sevilla, Sevilla 41012, Spain

\begin{abstract}
Vascular endothelial growth factor (VEGF) has been recently demonstrated to induce neuroprotective and synaptotrophic effects on lesioned neurons. Hitherto, the administration of VEGF in different animal models of lesion or disease has been conducted following a chronic protocol of administration. We questioned whether a single dose of VEGF, administered intraventricularly, could induce long-term neurotrophic effects on injured motoneurons. For this purpose, we performed in cats the axotomy of abducens motoneurons and the injection of VEGF into the fourth ventricle in the same surgical session and investigated the discharge characteristics of axotomized and treated motoneurons by single-unit extracellular recordings in the chronic alert preparation. We found that injured motoneurons treated with a single VEGF application discharged with normal characteristics, showing neuronal eye position (EP) and velocity sensitivities similar to control, thereby preventing the axotomy-induced alterations. These effects were present for a prolonged period of time (50 d) after VEGF administration. By confocal immunofluorescence we also showed that the synaptic stripping that ensues lesion was not present, rather motoneurons showed a normal synaptic coverage. Moreover, we demonstrated that VEGF did not lead to any angiogenic response pointing to a direct action of the factor on neurons. In summary, a single dose of VEFG administered just after motoneuron axotomy is able to prevent for a long time the axotomy-induced firing and synaptic alterations without any associated vascular sprouting. We consider that these data are of great relevance due to the potentiality of VEGF as a therapeutic agent in neuronal lesions and diseases.
\end{abstract}

Key words: angiogenesis; injured motoneurons; neurotrophic factors; oculomotor system; synaptic stripping

\section{Significance Statement}

Vascular endothelial growth factor (VEGF) is a novel neurotrophic factor whose chronic administration protects motoneurons from cell death in animal models of lesion or disease. Because of the promising therapeutic perspectives of this factor, it would be interesting to know whether a single dose could produce long-lasting effects on injured motoneurons. We pursued this issue by using a behaving chronic preparation showing that single intraventricular administration of VEGF prevented the firing and synaptic alterations induced by axotomy in abducens motoneurons without provoking an angiogenic response. These data demonstrate that VEGF administration does not require a continuous supply to obtain physiological improvements, data of great value due to its potential therapeutic use.

Received November 11, 2019; accepted March 23, 2020; First published May $5,2020$.

The authors declare no competing financial interests.

Author contributions: P.M.C., R.d.I.C., and A.M.P. performed research; P.M. C. analyzed data; R.d.I.C. and A.M.P. designed research; R.d.I.C. and A.M.P. wrote the paper.
This work was supported by Ministerio de Economía y CompetitividadFEDER (Grant reference: BFU2015-64515-P) in Spain and Ministerio de Ciencia, Innovación y Universidades (Grant reference: PGC2018-094654B-100). Confocal images were performed in the Central Research Services of University of Sevilla (CITIUS). P.M.C. was a scholar of Ministerio de Economía, Industria y Competitividad (BES-2016-077912) in Spain.

Acknowledgements: Confocal images were performed in the Central Research Services of University of Sevilla (CITIUS). 


\section{Introduction}

Vascular endothelial growth factor (VEGF) was initially characterized by its effects on the vascular system, promoting vasculogenesis and angiogenesis (Senger et al., 1983; Ferrara and Henzel, 1989; Yancopoulos et al., 2000). Interestingly, it has also been proven to be neuroprotective. Numerous works have demonstrated its trophic effects after different types of neuronal lesions (Pan et al., 2013; Beecher et al., 2018; Calvo et al., 2018; Zeng et al., 2018; Chi et al., 2019), excitotoxic injury (Matsuzaki et al., 2001; Tovar-y-Romo et al., 2007; Tovary-Romo and Tapia, 2010), ischemia (Sun et al., 2003; Guo et al., 2016; Geiseler and Morland, 2018; Wang et al., 2018), epilepsy (Nicoletti et al., 2008, 2010), and neurologic diseases such as motoneuronal degeneration in amyotrophic lateral sclerosis (ALS) and spinal-bulbar muscular atrophy (Kennedýs disease), peripheral neuropathies, Alzheimer's disease, Parkinson"s disease, demyelinating diseases, and also in traumatic spinal injury (enhancing nerve repair) and in neovascular ocular diseases (Storkebaum et al., 2005; Zachary, 2005; Wang et al., 2007, 2016; Lange et al., 2016; Guo et al., 2019). Although VEGF can act on different neuronal types (Storkebaum et al., 2004; Cabezas et al., 2019), a clear link has been established between VEGF and motoneurons (Lladó et al., 2013), mainly due to the appearance of symptoms resembling ALS when the levels of VEGF are low, as is the case for the $\mathrm{VEGF}^{\delta / \delta}$ mutant mice. These mice lack the hypoxia response element in the promotor region of the VEGF gene, so that as the animal matures the levels of VEGF decrease, leading to adult-onset motoneuron degeneration reminiscent of ALS (Oosthuyse et al., 2001). VEGF delivery to SOD ${ }^{G 93 A}$ transgenic mice (a classical model of ALS) by different gene therapies yields to a significant delay in the onset of motor deficits, slows motoneuron degeneration and prolongs survival (Azzouz et al., 2004; Wang et al., 2007, 2016). In human postmortem studies of ALS patients, the levels of VEGF and its receptors in the anterior horn cells of the spinal cord have been shown to be decreased (Brockington et al., 2006). Altogether, these works point to VEGF as a potent neurotrophic factor for motoneurons.

Previous studies supplying VEGF have delivered the factor chronically through different methods, such as osmotic pumps, viral vectors, genetic crossings with mice overexpressing VEGF, or repeated injections. Our recent work showed the effects of maintained supply of VEGF retrogradely via the proximal stump of the recessed abducens nerve (Calvo et al., 2018). Chronic VEGF retrograde supply produces the recovery of motoneuronal discharge activity and synaptic inputs altered by axotomy. In the present work, we aimed at determining the time span of

\footnotetext{
Correspondence should be addressed to Rosa R. de la Cruz at rmrcruz@ us.es.

https://doi.org/10.1523/ENEURO.0467-19.2020 Copyright @ 2020 Castrén et al.

This is an open-access article distributed under the terms of the Creative Commons Attribution 4.0 International license, which permits unrestricted use, distribution and reproduction in any medium provided that the original work is properly attributed.
}

the effects of VEGF after a single intraventricular application as a potential treatment route for neurologic diseases. We chose the abducens nucleus as a good model for studies of neuronal plasticity since its motoneurons can be recorded readily in the chronic alert animal preparation, and their normal discharge activity and synaptic inputs are well characterized (Delgado-Garcia et al., 1986; Escudero and Delgado-García, 1988; Escudero et al., 1992; Büttner-Ennever, 2006; Davis-López de Carrizosa et al., 2011). We sectioned the Vlth nerve at the orbital level in the same surgical session as the (single) administration of VEGF into the fourth ventricle, and thereafter, we performed a neurophysiological and synaptic study of the axotomized motoneurons. We have also evaluated whether the findings obtained after VEGF intraventricular administration can be explained by its well-known angiogenic activity, or rather indicate a direct neurotrophic action on neurons. Interestingly, we have found that a single administration of VEGF intraventricularly prevents the alterations induced by axotomy on the structure/function of abducens motoneurons for a prolonged period of time, and that these effects reflect a direct neurotrophic, nonangiogenic, activity of VEGF on motoneurons.

\section{Materials and Methods}

\section{Animals and surgical procedures}

Experiments were performed on adult female cats weighing $2.0-2.5 \mathrm{~kg}$ obtained from authorized suppliers (Universidad de Córdoba, Spain). All procedures were performed in accordance with the guidelines of the European Union (2010/63/EU) and the Spanish legislation (R.D. 53/ 2013, BOE 34/11370-421) for the use and care of laboratory animals and approved by the ethics committee.

A total of 11 animals was used in the present study. Three of these animals were prepared for extracellular single-unit recordings of abducens motoneurons. Motoneurons were recorded in the control situation as well as after axotomy plus VEGF treatment. The electrophysiological axotomy data were taken from our previous work by Calvo et al. (2018). In addition, in the present work we prepared eight additional animals for the morphologic study, which were not used for recordings to preserve an intact morphology: three control animals for the vascularization study (see below), two axotomized animals which were prepared exclusively for the morphologic study (one of them exclusively for the vascular study), and three animals which were axotomized and received VEGF intraventricularly. Data from two additional axotomized animals were taken from our previous study by Calvo et al. (2018).

A detailed description of the preparation for chronic recordings has been published previously (Davis-López de Carrizosa et al., 2009, 2010). Briefly, animals received an injection of atropine sulfate $(0.5 \mathrm{mg} / \mathrm{kg}$, i.m.) to reduce vagal reflexes, then they were anesthetized with ketamine hydrochloride $(20 \mathrm{mg} / \mathrm{kg}$, i.m.) mixed with xylazine $(0.5 \mathrm{mg} /$ $\mathrm{kg}$, i.m.) and placed in a stereotaxic frame. Two bipolar stimulating electrodes were implanted intracranially at the exit of both abducens (VIth) nerves from the brainstem (Fig. $1 A$, only left electrode illustrated) to allow the antidromic 


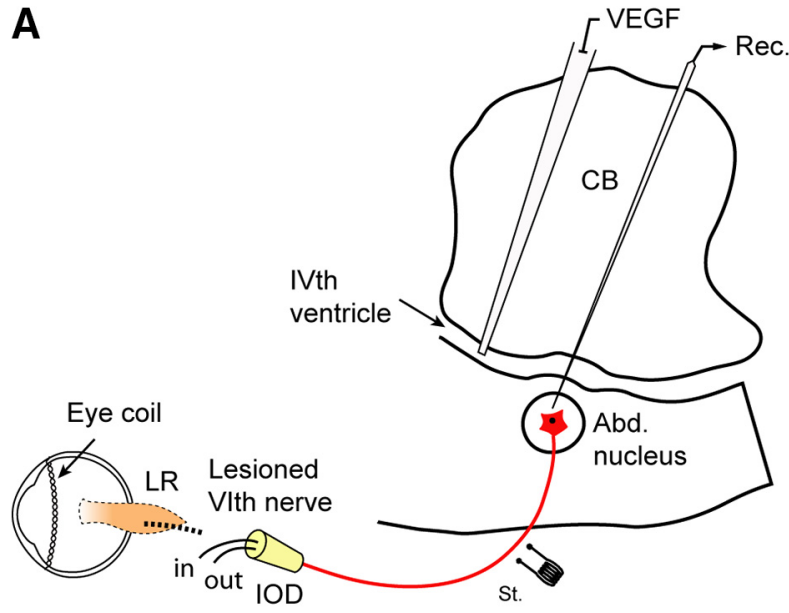

B Control Mn C Axotomized Mn D Ax+VEGF Mn

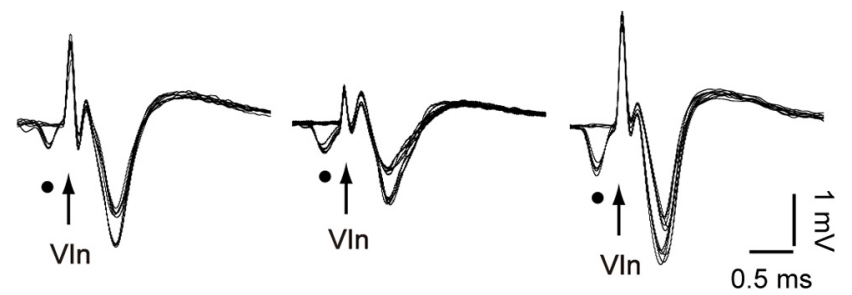

Figure 1. Experimental design and motoneuron identification. $\boldsymbol{A}$, Diagram illustrating the recording (Rec.) of abducens (Abd.) motoneurons identified by their antidromic activation from the electrode (St.) placed at the Vlth nerve. Abd. motoneurons of the left side were axotomized at the orbital level, the lateral rectus (LR) muscle removed and the nerve proximal stump inserted into the IOD to prevent reinnervation. In the same surgical session, VEGF was delivered by pressure injection into the VIth ventricle. Recordings and VEGF infusion were conducted through the cerebellum (CB). $\boldsymbol{B}-\boldsymbol{D}$, Collision tests were used for the identification of Abd. motoneurons (Mn). Three examples are shown: in $\boldsymbol{B}$, a control $\mathrm{Mn}$, in $\boldsymbol{C}$, an axotomized $\mathrm{Mn}(10 \mathrm{~d}$ after axotomy), and in $\boldsymbol{D}$, a $\mathrm{Mn}$ recorded $10 \mathrm{~d}$ after lesion and VEGF administration. The orthodromic spontaneous spikes are indicated by dots and the arrows point to the stimulus artifact.

identification of abducens motoneurons. Recordings were performed in the left abducens nucleus. Coils, made up of two turns of Teflon-isolated stainless-steel wire, were implanted in the sclera of both eyes to record eye movements, and a pedestal was constructed to facilitate head-fixed extracellular recordings. A square window $(5 \times 5 \mathrm{~mm})$ was drilled in the occipital bone to allow transcerebellar access to the brainstem for recordings (Fig. 1A). Postoperative care was provided daily, as needed.

\section{Chronic extracellular recordings}

Control recording sessions started $\sim 10 \mathrm{~d}$ after surgery. The animal was gently restrained inside a fabric bag, wrapped with elastic bandages, and placed in a Perspex box (with its head immobilized), which was located inside the magnetic field for eye movement recordings (Fuchs and Robinson, 1966). Single-unit extracellular recordings were conducted with glass micropipettes filled with $2 \mathrm{M}$ $\mathrm{NaCl}$, attached to a three-axis micromanipulator and advanced through the intact cerebellum to reach the brainstem (Fig. 1A). The (left) abducens nucleus was located by recording the antidromic field potential induced by electrical stimulation of the ipsilateral VIth nerve (Delgado-Garcia et al., 1986). All recorded abducens motoneurons of the present work were identified by their antidromic activation from the Vlth nerve followed by the collision test between the orthodromic and the antidromic spikes (Fig. 1B-D; examples for a control, an axotomized, and an axotomized + VEGF-treated motoneuron, respectively). After motoneuron identification, single-unit extracellular spikes were recorded simultaneously with eye movements under alert conditions. In some cells, the discharge activity during vestibularly-induced eye movements in the horizontal plane was also conducted. For this, the recording system rotated around the vertical axis by a servo-controlled motor attached to the turntable.

\section{Data storage and analysis}

The horizontal eye position (EP) of both eyes and simultaneous neuronal activity were digitally stored for off-line analysis (Power 1401, Cambridge Electronic Design). For data selection, computer programs written in MATLAB 7.5 displayed instantaneous firing frequency and the position of both eyes.

As previously described (Robinson 1970; Davis-López de Carrizosa et al., 2011), the firing rate (FR) of abducens motoneurons correlates with both EP and eye velocity (EV) according to the equation $F R=F_{0}+k \cdot E P+r \cdot E V$, where $k$ and $r$ are the position and velocity neuronal sensitivities, respectively, and $F_{0}$ is the FR at straight ahead gaze, i.e., when $\mathrm{EP}=0$ degrees.

FR during ocular fixations was fitted to the equation $F R=F_{0}+k_{s} E P$, since during eye fixations, EV is zero. The slope of the linear regression line obtained between FR and EP corresponded, therefore, to $k_{s}$ (neuronal EP sensitivity during spontaneous eye movements, in spikes/ second per degree). Relationships between neuronal FR and EV during spontaneous rapid eye movements, or saccades, were obtained by linear regression analysis, after the subtraction of the position component calculated from the previously known sensitivity to EP. Thus, the equation used was $F R-k_{s} \cdot E P-F_{0}=r_{s} \cdot E V$, where $r_{s}$ represents the neuronal EV sensitivity during saccades (in spikes/second per degree/second) and represents the slope of the rate-velocity regression line.

During vestibular stimulation, the equation used was $F R=F_{0}+k_{v} E P+r_{v} E V$. In this case, we used multiple linear regression analysis to calculate the neuronal sensitivities $k_{v}$ (in spikes/second per degree) and $r_{v}$ (in spikes/ second per degree/second) during vestibular eye movements. Only the slow phases of the nystagmus were selected between cursors for the analysis.

Because of the motor impairment of the eye ipsilateral to the axotomy, we used the eye movements of the contralateral (right) eye for computations. Previously, we demonstrated in control motoneurons that neuronal EP 
and velocity sensitivities during spontaneous and vestibularly-induced eye movements were similar when the analysis was performed with either the left or the right eye. This similarity in motoneuronal firing properties with either eye can be explained by the high degree of conjugacy in horizontal eye movements in the cat (de la Cruz et al., 2000; Davis-López de Carrizosa et al., 2009, 2010; Calvo et al., 2018).

\section{Axotomy and intraventricular administration of VEGF}

After the postoperative recovery, we performed several control recording sessions for approximately two weeks before lesion and VEGF administration. The animal was anesthetized (ketamine hydrochloride, $20 \mathrm{mg} / \mathrm{kg}$, i.m., mixed with xylazine, $0.5 \mathrm{mg} / \mathrm{kg}$, i.m.) and placed in a stereotaxic frame to perform the axotomy of the VIth nerve, as previously described in detail (Davis-López de Carrizosa et al., 2008, 2009; Calvo et al., 2018). Briefly, the left Vlth nerve was sectioned at its entrance into the lateral rectus muscle, which was removed, and an intraorbital device (IOD) implanted in the nerve stump. The proximal stump of the nerve was tightly introduced into the IOD, consisting in a custom-made conical chamber that had two pieces of tubing inserted for fluid replacement of the chamber with $0.01 \mathrm{~m}$ phosphate buffer, $\mathrm{pH} 7.4$, with $0.9 \%$ saline (PBS) every $48 \mathrm{~h}$. The IOD implantation also prevented the reinnervation of the severed nerve to any adjacent tissue, therefore allowing chronic axotomy.

VEGF was delivered in the fourth ventricle immediately after axotomy. We located the ventricle by lowering the recording micropipette through the cerebellum until an electrical activity silence in the recording was noticed just at the exit of the cerebellum (i.e., the IVth ventricle). Moreover, the entrance into the brainstem was also discernible by the mechanical pressure of the micropipette touching the brainstem. It is important to indicate that the abducens nucleus is located dorsally in the pons, at a distance of $\sim 1 \mathrm{~mm}$ below the floor of the fourth ventricle. For VEGF injection, we used a micropipette whose tip was beveled to a diameter of $\sim 20 \mu \mathrm{m}$. The micropipette was filled with the VEGF solution (recombinant rat VEGF ${ }_{164}$; R\&D Systems) containing PBS and $0.1 \%$ bovine serum albumin. We delivered at this position a single application of $1 \mu \mathrm{g}$ of VEGF in a total volume of $10 \mu \mathrm{l}$ by means of a pressure injector. Recording sessions of about $2 \mathrm{~h}$ each on alternate days restarted 2-4 $d$ after axotomy plus VEGF administration and lasted for a maximum of $50 \mathrm{~d}$.

\section{Immunocytochemical procedures}

We conducted immunofluorescence at the confocal microscopy level to evaluate the synaptic coverage in axotomized motoneurons treated with VEGF, as well as the possible angiogenic response to VEGF exogenous supply. In the three situations (control, axotomy, and axotomy plus intraventricular administration of VEGF), animals did not derive from the electrophysiological experiments.

Animals were deeply anesthetized (sodium pentobarbital, $100 \mathrm{mg} / \mathrm{kg}$, i.p.) $21 \mathrm{~d}$ after injury (with or without VEGF administration) for their transcardial perfusion with physiological saline followed by fixative (4\% paraformaldehyde in $0.1 \mathrm{~m}$ sodium phosphate buffer, $\mathrm{pH}$ 7.4). Following $2 \mathrm{~h}$ of postfixation, the brainstem at the level of abducens nucleus was cut at 50$\mu \mathrm{m}$-thick coronal sections on a vibratome and processed for immunocytochemistry.

Double immunofluorescence was conducted sequentially, that is, each primary antibody followed by its corresponding secondary antibody. Sections were first washed in PBS, pH 7.4, with $0.1 \%$ Triton X-100 (PBS/ $\mathrm{TX})$ and then blocked with normal donkey serum (1:10 in PBS/TX).

In all sections through the abducens nucleus, motoneurons were identified by their immunoreactivity against choline acetyltransferase (ChAT), obtained from goat (1:750; Millipore). Double immunofluorescence was conducted to combine ChAT immunostaining with other primary antibodies: either mouse monoclonal antibody against synaptophysin as a general marker of synaptic boutons (1:1000; Millipore), or mouse monoclonal antibody against GFAP to label astrocytes and their processes (1:400; Sigma-Aldrich).

In order to check the possibility that VEFG administration could mediate its neuronal effects, at least in part, through its well-known angiogenic activity, we characterized by immunocytochemistry the density of the vascular network in the abducens nucleus using an antibody against the glucose transporter 1 (GLUT-1), expressed selectively by endothelial cells of the blood-brain barrier (Krum et al., 2002; mouse monoclonal antibody, 1:1000; Millipore).

Secondary antibodies were obtained from Jackson ImmunoResearch, used at a dilution 1:50 in PBS/TX, and were the following: donkey anti-goat IgG coupled to TRITC (for ChAT detection) and donkey anti-mouse IgG coupled to FITC (for synaptophysin, GFAP, or GLUT-1) Finally, sections were rinsed in PBS, mounted on glass slides, and coverslipped with Dako fluorescence mounting medium (Dako North America).

Images were captured with a confocal laser scanning microscope (Zeiss LSM 7 DUO) at the same focal plane using different filters and later merged by using the Zeiss microscope software ZEN. Gray scales were adjusted to expand the maximum dynamic range of the image. Confocal images were analyzed by using the program Image $(\mathrm{NIH})$. For the quantification of the intensity of synaptophysin or GFAP immunostaining, two types of measurements were conducted by means of the program ImageJ, as previously described (Davis-López de Carrizosa et al., 2009, 2010; Morado-Díaz et al., 2014; Calvo et al., 2018). First, we measured the linear density of synaptophysin-immunoreactive (IR) boutons or GFAP-IR profiles surrounding the somata of ChAT-IR abducens motoneurons by using images captured at high magnification $(63 \times)$ in confocal planes containing the cell nucleus. The percentage of the total perimeter of the ChAT-IR cell body occupied by synaptophysin-IR or GFAP-IR profiles was measured as an index of the linear density of the immunolabeling. Second, the intensity of synaptophysin or GFAP immunolabeling was measured also in the neuropil of the abducens nucleus using $4 \times 4$ tile images captured at $20 \times$. Mean gray value 
(optical density) was considered as an index of the intensity of immunolabeling in the abducens neuropil (the area surrounding abducens motoneurons) and was analyzed as the average gray value of 20 square boxes of $42-\mu \mathrm{m}$ side per image, after background subtraction. Data obtained in the neuropil were then normalized with respect to control.

To evaluate the possibility of an angiogenic response to VEGF treatment, we measured, in the three situations (control, axotomy, axotomy + VEGF), three different vascular parameters (blood vessels identified as GLUT-1-IR) in the abducens nucleus (delimited by the ChAT labeling), in all cases by stereology using a grid pattern to measure only those vessels interacting with the grid to avoid subjective bias (Croll et al., 2004; Nicoletti et al., 2008), by means of the ImageJ program. First, we measured vascular density as the area of vessels relative to the total area of the abducens nucleus (in \%). Moreover, we also compared vessel lumen size between the three situations by measuring the diameter of the blood vessels, as described in detail previously (Croll et al., 2004; Nicoletti et al., 2008) and also used by others (Oosthuyse et al., 2001; Azzouz et al., 2004). A third measurement of vasculature consisted in counting the number of blood vessels as has been used previously (Oosthuyse et al., 2001), and expressed relative to unit area $\left(2500 \mu \mathrm{m}^{2}\right)$ by a stereology procedure using regions of interest (ROIs) of $2500 \mu \mathrm{m}^{2}$. The number of animals for the vasculature analysis was the following: $n=3$ for control, $n=4$ for axotomy, and $n=3$ for axotomy + VEGF. All quantification of fluorescent images, including synaptic, GFAP, and vascular measurements, were conducted by experimenters blind to the different groups of animals (i.e., control, axotomy, and axotomy + VEGF).

\section{Statistics}

Results between groups were statistically contrasted by using one-way or two-way ANOVA tests, in all cases at an overall level of significance of $p<0.05$. ANOVA tests were followed by post hoc pairwise multiple comparisons using the Holm-Sidak method. The statistical program used was SigmaPlot version 11 (Systat Software). Data were expressed as mean \pm SEM.

\section{Results}

\section{VEGF prevents axotomy-induced alterations on motoneuron discharge during spontaneous eye movements}

The discharge activity of abducens motoneurons highly correlates with EP and velocity, as previously reported (Delgado-Garcia et al., 1986; Davis-López de Carrizosa et al., 2011). Thus, a tonic firing is present during eye fixations, which increases as the eye moves toward the ipsilateral side (i.e., the on direction; in our case leftwards), and decreases for fixations in the off direction (Fig. 2A). Similarly, when the eye performs a rapid eye movement, or saccade, in the on-direction, motoneurons discharge a high-frequency burst of action potentials, whereas they stop firing or exhibit an abrupt drop in FR for off-directed saccades (Fig. 2A). Therefore, abducens motoneurons display a tonic-phasic discharge pattern during spontaneous eye movements.

The discharge of axotomized abducens motoneurons changed noticeably. Injured motoneurons discharged at lower firing frequencies than in control, during both the static and the dynamic components of the discharge (Fig. $2 B$ ). The absence of high-frequency bursts during on-directed saccades was very conspicuous, instead a weak increase in firing was observed during this type of eye movements (Fig. 2B). VEGF administration prevented all these lesion-induced alterations in axotomized motoneurons. Figure $2 C, D$ illustrates the discharge activity of two motoneurons recorded $18 \mathrm{~d}$ (Fig. 2C) or $38 \mathrm{~d}$ (Fig. 2D) after axotomy + VEGF delivery. As can be observed, their discharge pattern resembled that of control motoneurons (compare Fig. 2C,D and $A$ ). It is important to emphasize that: (1) all motoneurons recorded after VEGF delivery exhibited, from a qualitative perspective, a firing pattern similar to control throughout the entire period of experimental recordings (50 d), and (2) VEGF administration was acute, that is, it was supplied only once and just at the time of axotomy.

Motoneuronal EP sensitivity $\left(k_{s}\right.$, in spikes/second per degree) was obtained as the slope of the rate-position plot during eye fixations. Linear regression lines of the rate-position plot for the four motoneurons illustrated in Figure $2 A-D$ are shown in Figure $2 E$. Except for the untreated axotomized motoneuron, whose $\mathrm{k}_{\mathrm{s}}$ value was low (4.5 spikes/s per degree), the motoneurons that received the single dose of VEGF, either at $18\left(\mathrm{k}_{\mathrm{s}}=9.6 \mathrm{spikes} / \mathrm{s}\right.$ per degree) or $38 \mathrm{~d}$ post-VEGF ( $\mathrm{k}_{\mathrm{s}}=7.48 \mathrm{spikes} / \mathrm{s}$ per degree), showed rate-position slopes and, therefore, $\mathrm{k}_{\mathrm{s}}$ values, similar to the control motoneuron $\left(k_{s}=7.85\right.$ spikes $/ \mathrm{s}$ per degree; Fig. 2E).

The same happened for the motoneuronal EV sensitivity $\left(r_{s}\right.$, in spikes/second per degree/second) during saccades, the slope of the regression line obtained between FR, previous subtraction of the EP component, and EV (Fig. 2F). For the motoneurons illustrated in Figure $2 A-D$, we obtained that after VEGF administration, $r_{\mathrm{s}}$ values (1.4 and 1.36 spikes/s per degree/s, for the motoneurons recorded at 18 and $38 \mathrm{~d}$ post-VEGF, respectively) were similar to control (0.93 spikes/s per degree/s), whereas the $r_{s}$ of the axotomized motoneuron differed clearly showing a lower value $\left(r_{s}=0.30\right.$ spikes/s per degree/s; Fig. 2F).

\section{VEGF neurotrophic effects on axotomized motoneurons are long-lasting}

The time course of changes in $\mathrm{k}_{\mathrm{s}}$ and $\mathrm{r}_{\mathrm{s}}$ in motoneurons was evaluated in the two experimental conditions: axotomy only and axotomy plus a single dose of intraventricular VEGF. As a first approximation, we elaborated a graph displaying over time the values of $\mathrm{k}_{\mathrm{s}}$ (Fig. $3 A$ ) and $\mathrm{r}_{\mathrm{s}}$ (Fig. $3 B$ ) of the motoneurons recorded in each condition. It can be observed that the great majority of $\mathrm{k}_{\mathrm{s}}$ and $\mathrm{r}_{\mathrm{s}}$ data in the VEGF-treated motoneurons appeared distributed within the mean $\pm S D$ of the control group of motoneurons (Fig. $3 A, B)$. In contrast, axotomized motoneurons presented lower $k_{s}$ and $r_{s}$ values, which in many cases appeared below the mean minus 1 SD of control data. Although our 

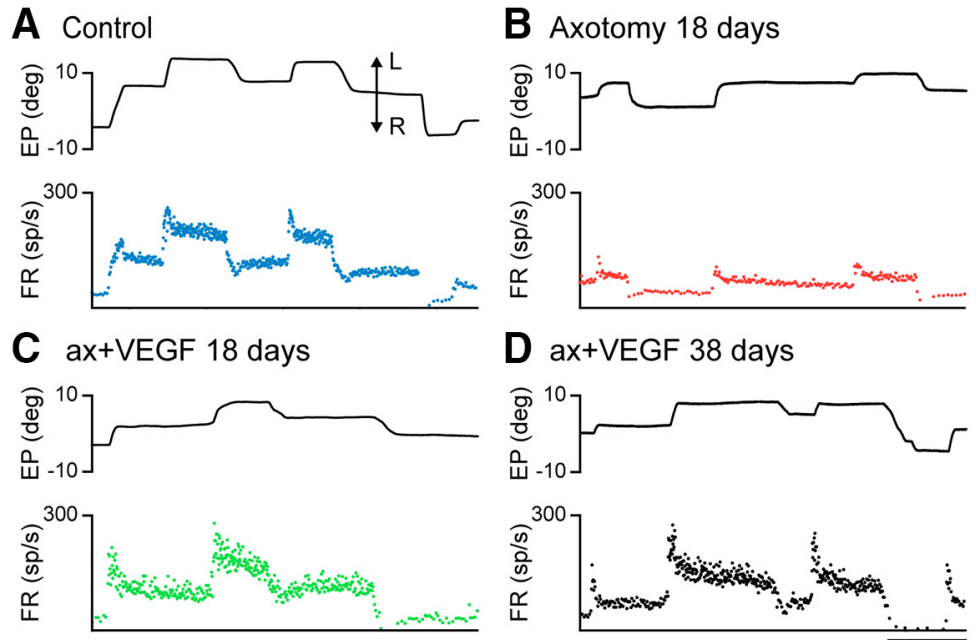

D ax+VEGF 38 days
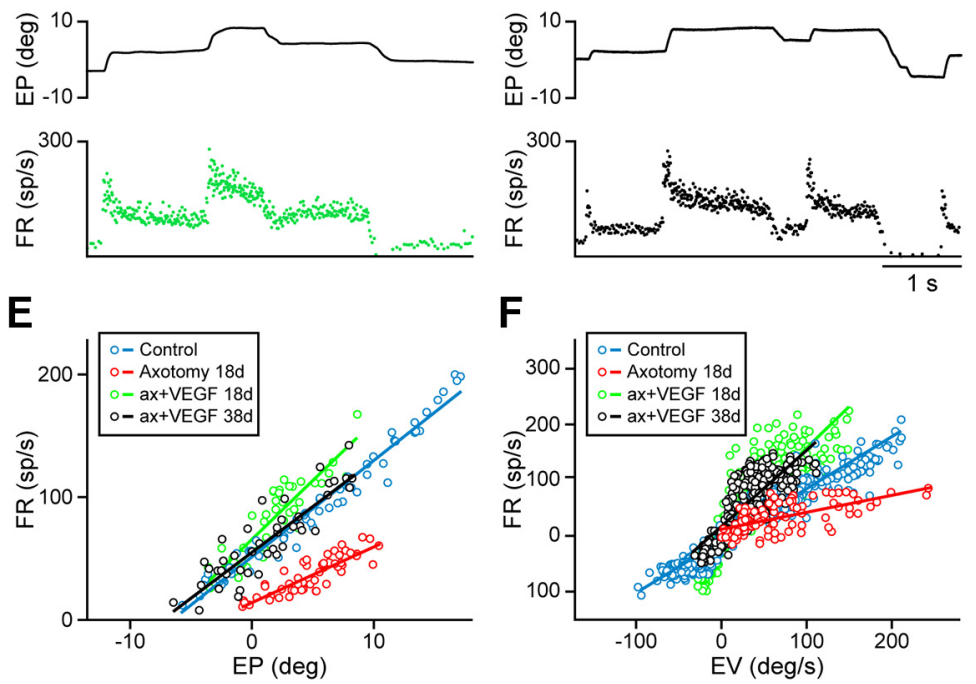

Figure 2. Discharge pattern of motoneurons during spontaneous eye movements. $\boldsymbol{A}$, Example of a control motoneuron showing its FR (in spikes/second) recorded simultaneously with EP (in degrees). A typical tonic-phasic discharge activity can be appreciated. Leftwards $(\mathrm{L})$ and rightwards $(\mathrm{R})$ eye movements are indicated by the double arrow. $\boldsymbol{B}$, Axotomized motoneurons discharged at lower rates showing the partial loss of the static and dynamic components of their firing. The illustrated cell corresponds to a motoneuron recorded $18 \mathrm{~d}$ after axotomy. $\boldsymbol{C}$, Example of a motoneuron recorded $18 \mathrm{~d}$ after axotomy + VEGF administration showing a firing pattern similar to control. $\boldsymbol{D}$, Same as $\boldsymbol{C}$ but for a motoneuron recorded $38 \mathrm{~d}$ after axotomy and VEGF. $\boldsymbol{E}$, Plots showing firing rate versus EP during fixations for the motoneurons shown in $\boldsymbol{A}-\boldsymbol{D}$. The slope of each regression line corresponds to the EP sensitivity for that motoneuron ( $\mathrm{k}_{\mathrm{s}}$, in spikes/s per degree). $\boldsymbol{F}$, Regression lines obtained between FR (minus the EP component) and EV (in degrees/second) during saccades for the same four motoneurons in $\boldsymbol{A}-\boldsymbol{D}$. The slope of these regression lines corresponds to the EV sensitivity $\left(r_{\mathrm{s}}\right.$, in spikes/second per degree/second).

data of axotomy were obtained only during $21 \mathrm{~d}$ after lesion (Calvo et al., 2018), it has been previously described that chronic axotomy produces long-lasting changes as long as reinnervation is not allowed (Delgado-Garcia et al., 1988). Therefore, as a first approximation, these data showed similar $\mathrm{k}_{\mathrm{s}}$ (Fig. $3 A$ ) and $\mathrm{r}_{\mathrm{s}}$ (Fig. 3B) values in the VEGF-treated motoneurons as compared with the control cells and, in addition, this similarity remained throughout the experiment.

To further evaluate whether the single administration of VEGF led to a long-time recovery, motoneurons were grouped in week intervals beginning from the day of surgery (i.e., the day when axotomy plus VEGF intraventricular injection was performed) until the last week of recordings (seventh week), and mean $k_{s}$ and $r_{s}$ values were calculated per week and compared with control (Fig. $3 C, D)$. The overall comparison of the $\mathrm{k}_{\mathrm{s}}$ values obtained per week after treatment along with the control data revealed similarity between groups (one-way ANOVA, $F_{(7,253)}=1.251, p=0.275 ; n$ ranged between 12 and 40 motoneurons per week; for control $n=64$ ), therefore indicating the absence of any change in $\mathrm{k}_{\mathrm{s}}$ over time, and similarity of all groups in relation to control (Fig. $3 C$ ). In contrast, axotomy data grouped per week were significantly lower than the VEGF data for the same week [for $\mathrm{k}_{\mathrm{s}}$ : two-way ANOVA, $F_{(5,141)}=69.465, p<0.001$ (Fig. $3 C)$; for $r_{s}$ : two-way ANOVA, $F_{(5,141)}=28.732, p<0.001$ (Fig. 3D)]. Of especial relevance was the fact that $k_{s}$ did not fall toward lower values at long periods after VEGF application, and therefore motoneuronal EP sensitivity did not return to the axotomy situation. For $r_{s}$ values, we obtained similar results. Thus, the data grouped per week plus the control group were compared with each other, and the results of this comparison revealed absence of any statistically significant difference (one-way ANOVA, $F_{(7,253)}=1.341, p=0.231$; same $n$ as for $\mathrm{k}_{\mathrm{s}}$ data, see above). Therefore, as can be appreciated in Figure $3 D$, there was no tendency in $r_{s}$ values to decrease with time after treatment.

Since no differences were found in $k_{s}$ and $r_{s}$ over time, we grouped all motoneurons recorded during each situation: control $(n=64)$, axotomy alone $(n=57)$, or axotomy plus VEGF delivery $(n=199)$, and calculated their respective $k_{s}$ and $r_{s}$ mean values. The results obtained indicated 

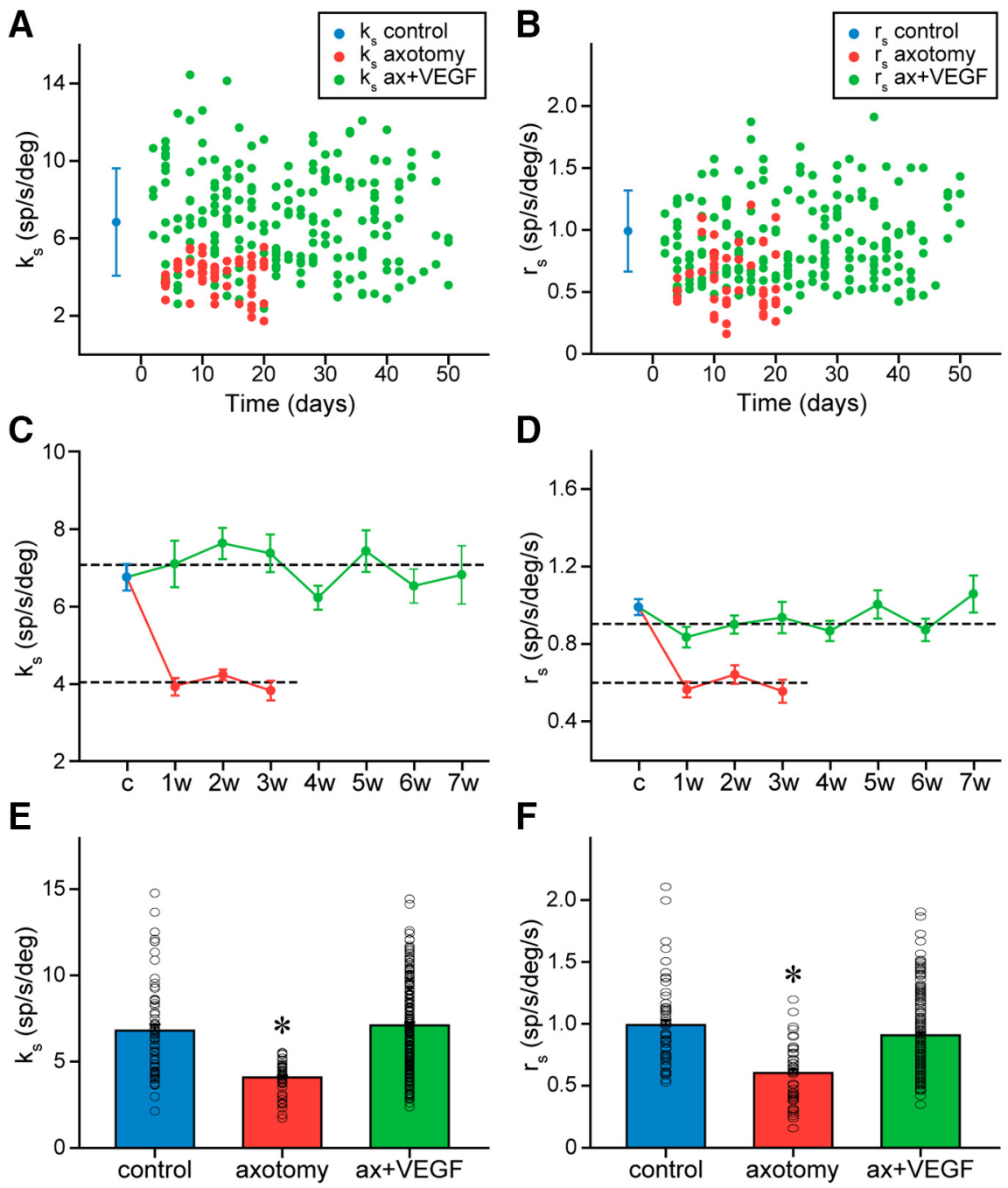

Figure 3. Time course of changes in EP and velocity sensitivities during spontaneous eye movements after axotomy and VEGF administration. $\boldsymbol{A}$, EP sensitivities $\left(\mathrm{k}_{\mathrm{s}}\right)$ of motoneurons recorded at the indicated days after axotomy (red dots; lesion corresponds to time 0) and after axotomy followed by VEGF administration (green dots). The mean control value (solid dot, in blue) and its SD (blue bars) are shown at the left of the graph. $\boldsymbol{B}$, Same as $\boldsymbol{A}$, but for EV sensitivity $\left(r_{s}\right)$. $\boldsymbol{C}$, Mean \pm SEM of $k_{s}$ values for the control population (c) and at different weeks (w) after either axotomy (in red) or axotomy plus the single VEGF delivery (in green). Horizontal dashed lines represent the a alone (lower line). There were significant differences between axotomy and VEGF groups comparing per week (two-way ANOVA, $p<0.001$ ). $\boldsymbol{D}$, Same as $\boldsymbol{C}$, but for $r_{\mathrm{s}}$. No significant differences were found between the mean values obtained per week after the supply of VEGF for $\mathrm{k}_{\mathrm{s}}(\boldsymbol{C}$; one-way ANOVA, $p=0.275)$ or $\mathrm{r}_{\mathrm{s}}(\boldsymbol{D}$; one-way ANOVA, $p=0.201)$. For $\boldsymbol{C}, \boldsymbol{D}$, the number of motoneurons recorded at the different weeks after treatment ranged between 12 and 40, and for axotomy between 8 and $28 ; n=64$ control motoneurons. $\boldsymbol{E}$, Bar chart illustrating $\mathrm{k}_{\mathrm{s}}$ data and its mean value for in the population of motoneurons recorded in the control situation, after only axotomy and after axotomy plus VEGF administration. The asterisk indicates significant difference between the axotomy and control groups (one-way ANOVA, $p<0.001$ ). On the contrary, the VEGF-treated group showed no significant difference with control $(p=0.437)$. $\boldsymbol{F}$, Same as $\boldsymbol{E}$, but for $r_{\mathrm{s}}$ values. The axotomy group showed a significant difference in $r_{\mathrm{s}}$ with respect to control (asterisk, one-way ANOVA, $p<0.001$ ), whereas the VEGF-treated group was similar to control $(p=0.064)$. For $\boldsymbol{E}$, $\boldsymbol{F}$, the number of motoneurons analyzed in each situation was $n=64,57$, and 199 for the control, axotomy, and VEGF-treated groups, respectively.

statistically significant differences $\left[k_{\mathrm{s}}\right.$ : one-way ANOVA, $F_{(2,317)}=35.674, p<0.001$ (Fig. 3E); $r_{s}$ : one-way ANOVA, $F_{(2,317)}=26.196, p<0.001$ (Fig. 3F)] so that $\mathrm{k}_{\mathrm{s}}$ and $\mathrm{r}_{\mathrm{s}}$ of axotomized motoneurons were significantly $(p<0.001)$ lower than control, whereas the values obtained after the administration of VEGF were similar to control $(p=0.437$ for $\mathrm{k}_{\mathrm{s}}$ and $p=0.072$ for $\mathrm{r}_{\mathrm{s}}$ ). Altogether, these results indicated that a single dose of VEGF prevented for a long time the changes induced by axotomy in the EP and velocity sensitivities of motoneurons during spontaneous eye movements.

\section{Vestibular signals remain normal in axotomized motoneurons after a single dose of VEGF}

During vestibularly-induced eye movements produced by horizontal rotation of the table, abducens motoneurons discharged in correlation with EP and EV as previously 
A Control

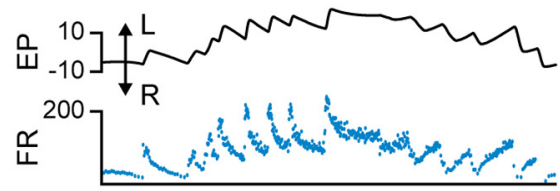

C ax+VEGF 4 days
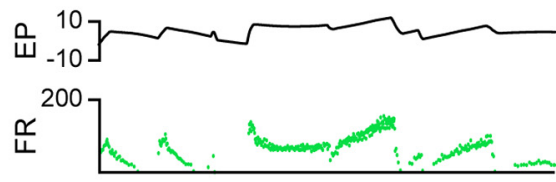

E

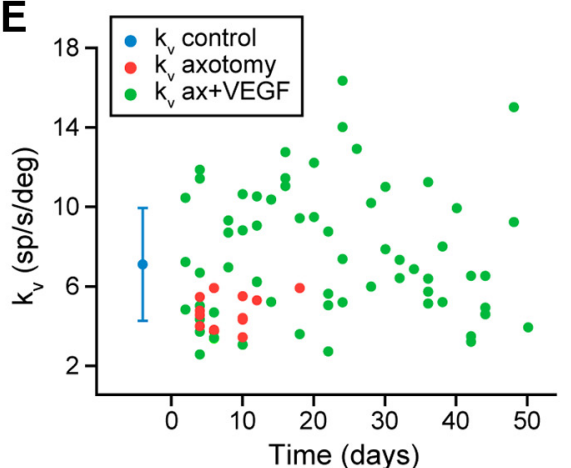

G

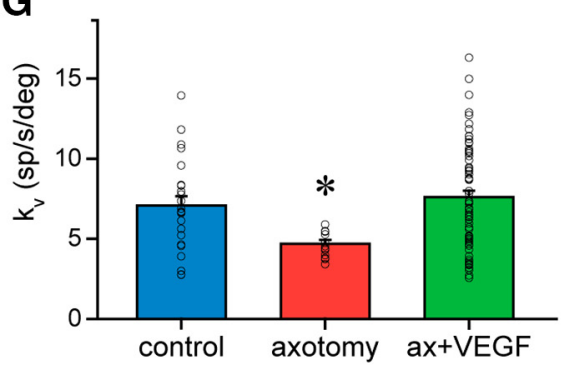

B Axotomy 4 days
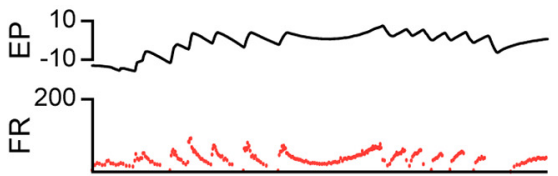

D ax+VEGF 36 days
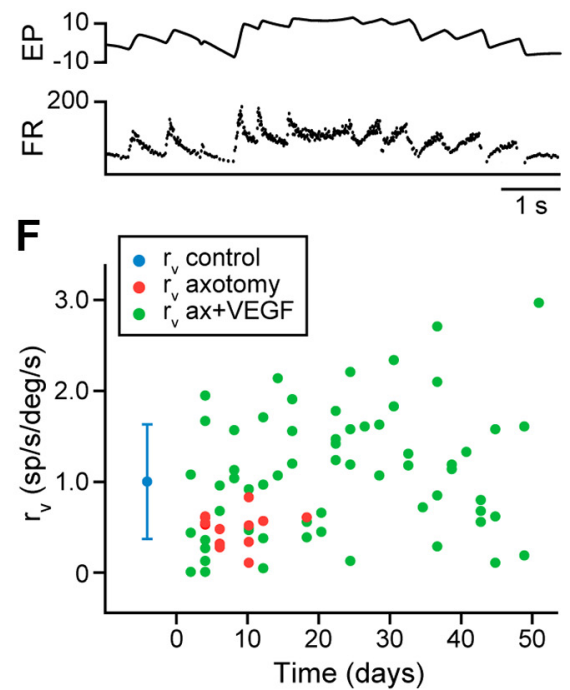

H

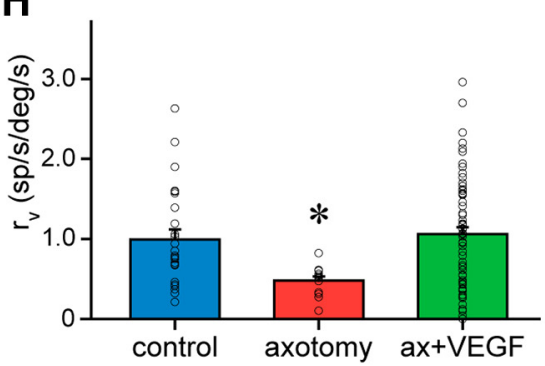

Figure 4. Behavior of abducens motoneurons during vestibularly-induced eye movements. $\boldsymbol{A}-\boldsymbol{D}$, Examples of motoneurons recorded during vestibular eye movements in control $(\boldsymbol{A})$, axotomy (B; $4 \mathrm{~d}$ after lesion), and after VEGF administration (C; $4 \mathrm{~d}$ and $\boldsymbol{D}$; $36 \mathrm{~d}$ ). Traces correspond to EP (in degrees) and FR (in spikes/second). Eye movements to the left (L) are upwards in the EP trace (double arrow). $\boldsymbol{E}, \boldsymbol{F}$, Time course of changes in EP $\left(\mathrm{k}_{\mathrm{v}} ; \boldsymbol{E}\right)$ and $\mathrm{EV}\left(\mathrm{r}_{\mathrm{v}} ; \boldsymbol{F}\right)$ during vestibular eye movements. Control data (mean $\left.\pm \mathrm{SD}\right)$ are indicated by a blue dot and bars. $k_{v}$ and $r_{v}$ values for the axotomized population are indicated by red dots in $\boldsymbol{E}$, $\boldsymbol{F}$, respectively, as a function of time following the day of lesion (day 0). For VEGF-treated motoneurons, $\mathrm{k}_{\mathrm{v}}$ data are illustrated in $\boldsymbol{E}$ (green dots) and those of $r_{v}$ in $\boldsymbol{F}$ (green dots) throughout time after the day of surgery (lesion plus VEGF administration, day 0 ). $\boldsymbol{G}, \boldsymbol{H}$, All the population of control $(n=25)$, axotomized $(n=13)$ or VEGF-treated motoneurons $(n=64)$ recorded during vestibular eye movements were grouped in three pools, and their EP $\left(\mathrm{k}_{\mathrm{v}} ; \boldsymbol{G}\right)$ and EV $\left(\mathrm{r}_{\mathrm{v}} ; \boldsymbol{H}\right)$ sensitivities were compared. For $\mathrm{k}_{\mathrm{v}}$, axotomized motoneurons showed a significantly lower sensitivity as compared with control (G; asterisk; one-way ANOVA, $p=0.021)$, whereas similar $k_{v}$ values were found between control and VEGF-treated motoneurons $\left(\boldsymbol{G} ; \boldsymbol{p}=\mathbf{0 . 4 7 0}\right.$ ). The same happened for $r_{v}$ (in $\boldsymbol{H}$ ): axotomized motoneurons presented a significantly lower value than control (asterisk; one-way ANOVA, $p=0.021$ ), but motoneurons of the VEGF group showed $r_{v}$ values similar to control $(p=0.657)$.

described (Delgado-Garcia et al., 1986; Fuchs et al., 1988; Davis-López de Carrizosa et al., 2009, 2010). Control motoneurons increased their discharge for ipsilateral eye movements during both the slow and the fast phases of the vestibulo-ocular reflex, and reduced their FR for eye movements in the opposite direction (Fig. 4A). In contrast, axotomy led to a significant reduction in motoneuronal discharge during vestibular eye movements (Fig. $4 B$ ). When VEGF was applied in the fourth ventricle immediately after axotomy, motoneurons recorded thereafter showed a normal discharge pattern during vestibular eye movements that resembled the pattern observed in control. Axotomized VEGF-treated motoneurons behaved normally throughout the whole period of recordings after VEGF administration (50 d), as illustrated for the two examples of motoneurons recorded 4 and $36 \mathrm{~d}$ after VEGF administration (Fig. $4 C, D$, respectively).

We analyzed EP and EV sensitivities $\left(k_{v}\right.$ and $r_{v}$, respectively) during the slow phases of the nystagmus in control, axotomized and VEGF-treated motoneurons. As shown in 

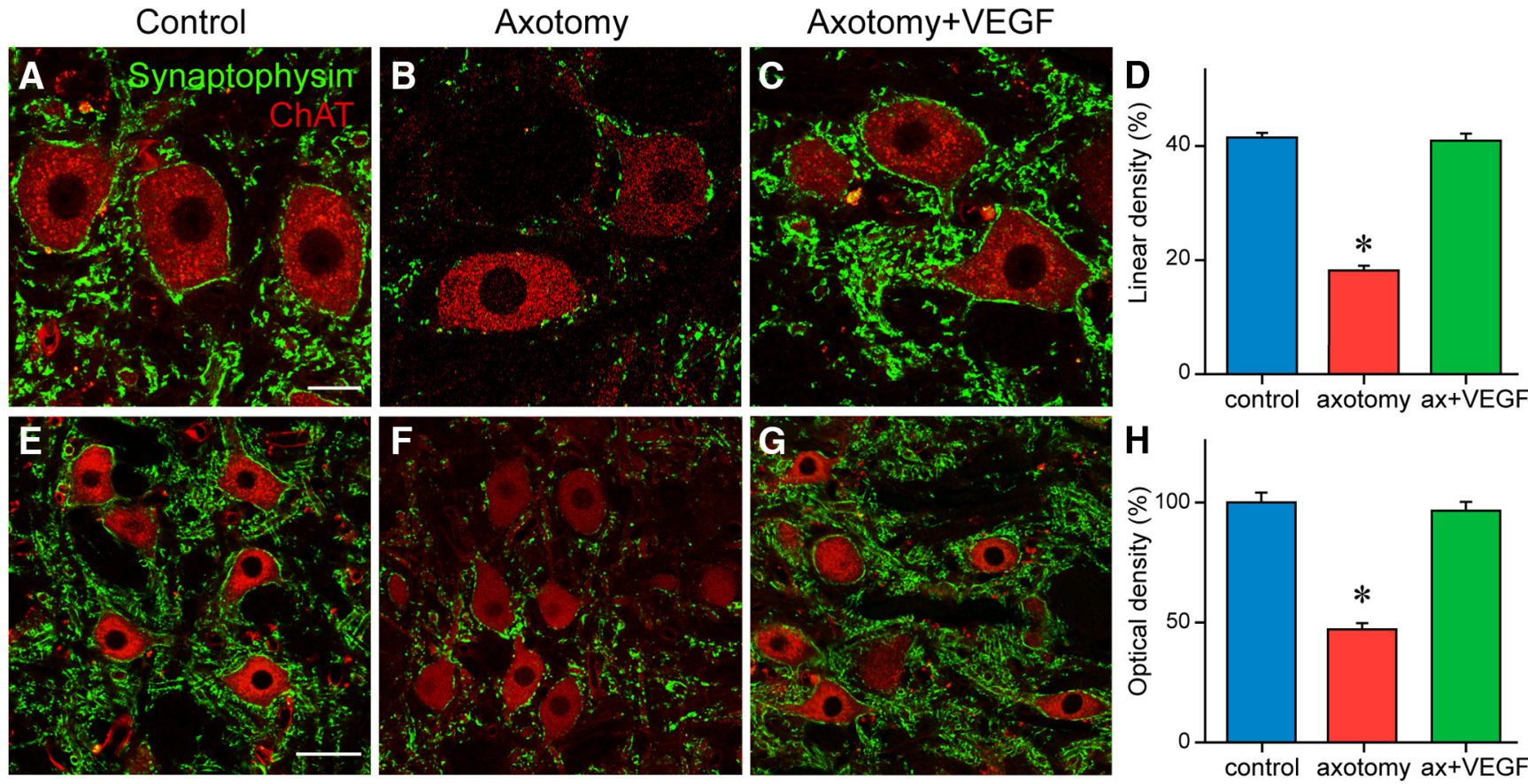

Figure 5. VEGF prevents the synaptic loss induced by axotomy. Confocal images obtained after double immunofluorescence against ChAT, to label the motoneurons, and synaptophysin, to label synaptic boutons, around cell bodies $(\boldsymbol{A}-\boldsymbol{C})$ and in the neuropil $(\boldsymbol{E}-\boldsymbol{G})$. Images are shown for control $(\boldsymbol{A}, \boldsymbol{E})$, axotomy $(\boldsymbol{B}, \boldsymbol{F})$, and after axotomy + VEGF supply $(\boldsymbol{C}, \boldsymbol{G})$. $\boldsymbol{D}$, Bar chart illustrating the percentage of the somatic perimeter of motoneurons covered by synaptophysin-positive boutons (i.e., linear density) in the three situations. The statistical analysis revealed a significant $(p<0.001)$ decrease in synaptic coverage after axotomy as compared with control (asterisk), whereas data obtained after VEGF delivery were similar $(p=0.703)$ to control (one-way ANOVA). $\boldsymbol{H}$, Same as $\boldsymbol{D}$ but for measurements of synaptophysin optical density in the neuropil of the abducens nucleus. Axotomy induced also a significant $(p<0.001)$ decrease (asterisk) in synaptic boutons at the neuropil level, but VEGF administration prevented this reduction producing values similar $(p=0.503$ ) to control (one-way ANOVA). For $\boldsymbol{D}, \boldsymbol{H}$, mean \pm SEM are illustrated. Scale bars: $20 \mu \mathrm{m}$ in $\boldsymbol{A}$ (for $\boldsymbol{A}-\boldsymbol{C})$ and $50 \mu \mathrm{m}$ in $\boldsymbol{E}$ (for $\boldsymbol{E}-\boldsymbol{G})$.

Figure $4 E, F, \mathrm{k}_{\mathrm{v}}$ and $\mathrm{r}_{\mathrm{v}}$ values of axotomized cells were low in comparison with control (mean $\pm S D$ ), whereas those of injured motoneurons that received VEGF appeared similar to control. In addition, it can be observed that these parameters were maintained within a normal range in the VEGF-treated motoneurons throughout the whole period of recordings. Pooling the motoneurons per week after VEGF delivery, we found no significant difference between the seven VEGF groups (from the first to the seventh week) and control ( $k_{v}$ : one-way ANOVA, $F_{(7,81)}=$ $1.442, p=0.2 ; r_{\mathrm{v}}$ : one-way ANOVA, $F_{(7,81)}=1.535$, $p=0.167 ; n$ ranged between 5 and 13 treated motoneurons per week, and for the control group $n=25$; not illustrated). Therefore, we clustered the motoneurons in three groups: control, axotomy alone, and axotomy plus VEGF delivery. Comparison between groups revealed significant differences between groups [for $\mathrm{k}_{\mathrm{v}}$ : one-way ANOVA, $F_{(2,99)}=5.121, p=0.008$ (Fig. $4 G$ ); for $r_{v}$ : one-way ANOVA, $F_{(2,99)}=4.490, p=0.014 ; n=25,13$, and 64 motoneurons for control, axotomy, and VEGF groups, respectively (Fig. 4H)]. In particular, axotomized motoneurons presented significantly lower $\mathrm{k}_{\mathrm{v}}\left(p=0.021\right.$; Fig. 4G) and $\mathrm{r}_{\mathrm{v}}$ $(p=0.021$; Fig. $4 H)$ values than control, whereas injured motoneurons treated with VEGF had $\mathrm{k}_{\mathrm{v}}(p=0.470$; Fig. $4 G)$ and $r_{v}(p=0.657$; Fig. $4 H)$ values similar to control cells. Therefore, as happened for spontaneous eye movements, a single dose of VEGF applied to axotomized motoneurons was able to prevent the alterations in motoneuronal sensitivities to EP and EV during vestibularly-induced eye movements for a prolonged period of time.

\section{Synaptic density is preserved in the long-term after a single pulse of VEGF to axotomized motoneurons}

Synaptophysin immunoreactivity was used as a general marker of synaptic boutons. We quantified the percentage of the somatic perimeter of abducens motoneurons that appeared contacted by synaptophysin-positive boutons, an index of linear density (in \%) $21 \mathrm{~d}$ after lesion (with or without VEGF). A simple inspection of synaptophysin-IR boutons in the three situations revealed that control motoneurons presented a high density of perisomatic boutons (Fig. 5A) that contrasted with the low synaptophysin-IR boutons contacting axotomized motoneurons (Fig. 5B). In contrast, VEGF-treated motoneurons showed a normal density of synaptophysin-positive boutons contacting their somatic perimeter that resembled that found in control (Fig. 5C). Quantification of the linear density of synaptophysin-immunostained terminals (Fig. 5D) revealed significant differences between groups (one-way ANOVA, $F_{(2,191)}=$ 144.762, $p<0.001)$. Thus, control motoneurons $(n=69)$ presented a somatic synaptic coverage of $41.44 \pm 0.84 \%$, whereas in axotomized cells $(n=54)$, synaptic coverage fell 

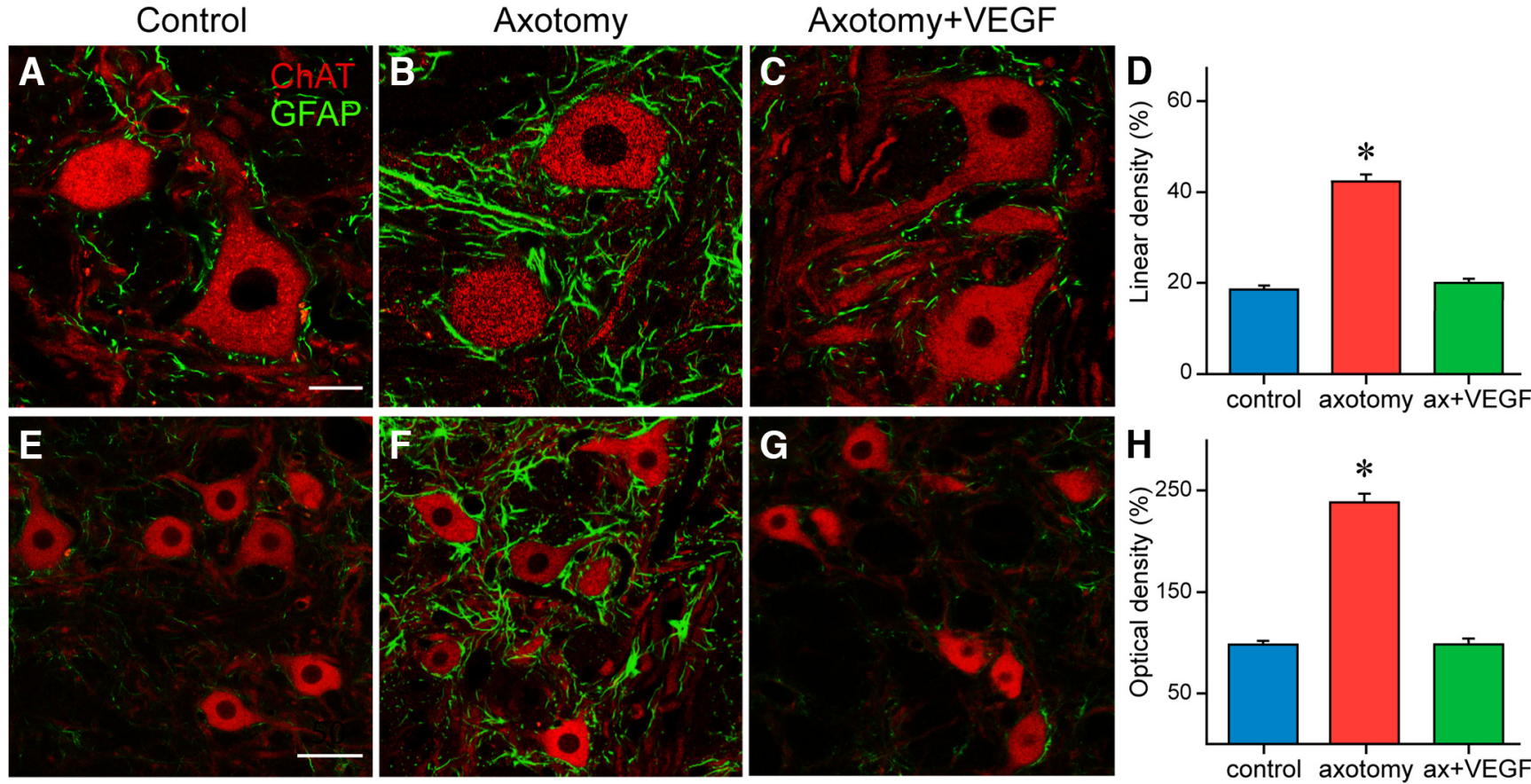

Figure 6. VEGF abolishes the astroglial reaction induced by axotomy. Confocal images of double immunofluorescence for GFAP, as a marker of astrocytes, and ChAT, as a marker of motoneurons, both at the level of the cell bodies $(\boldsymbol{A}-\boldsymbol{C})$ and in the abducens neuropil $(\boldsymbol{E}-\boldsymbol{G})$. The three situations are shown: control $(\boldsymbol{A}, \boldsymbol{E})$, axotomy $(\boldsymbol{B}, \boldsymbol{F})$, and post-VEGF $(\boldsymbol{C}, \boldsymbol{G})$. $\boldsymbol{D}, \boldsymbol{H}$, Bar charts illustrating the percentage of motoneuron somata covered by GFAP-IR profiles (i.e., lineal density; $\boldsymbol{D}$ ), and the intensity of GFAP immunostaining (i.e., optical density; $\boldsymbol{H}$ ) in the abducens neuropil. After axotomy, there was a significant increase (asterisk) in both lineal ( $\boldsymbol{D}$; $p<0.001)$ and optical $(\boldsymbol{H} ; p<0.001)$ density as compared with control data. However, VEGF delivery blocked the astroglial response to lesion, since values obtained after VEGF were similar $(\boldsymbol{p}=0.349 ; \boldsymbol{D}$ and $p=0.963 ; \boldsymbol{H})$ to control (one-way ANOVA). Data correspond to mean \pm SEM. Scale bars: $20 \mu \mathrm{m}$ in $\boldsymbol{A}$ (for $\boldsymbol{A}-\boldsymbol{C}$ ) and $50 \mu \mathrm{m}$ in $\boldsymbol{E}$ (for $\boldsymbol{E}-\boldsymbol{G}$ ).

to $18.12 \pm 0.97 \%$, which resulted in a significant difference $(p<0.001)$. In contrast, injured cells that received a single dose of VEGF showed $21 \mathrm{~d}$ later $(n=71)$ a normal synaptic coverage $(40.90 \pm 1.24 \%)$ around their cell bodies that was similar to control ( $p=0.703$; Fig. $5 D$ ).

A quantification of the intensity of synaptophysin immunoreactivity (i.e., optical density, in percentage with respect to control) was also performed at the level of the neuropil (the area between labeled motoneurons). Results were similar to those described above for the cell bodies. Therefore, neuropil immunostaining of synaptophysin after treatment with VEGF (Fig. 5G) was similar to control $(p=0.503$; Fig. $5 E, H)$, in contrast to the lower intensity obtained in the injured abducens neuropil $(p<0.001$; Fig. $5 F)$. The statistical analysis confirmed these observations (one-way ANOVA, $F_{(2,417)}=58.371, p<0.001 ; n=180$, 120 , and 120 for control, axotomy, and VEGF, respectively; Fig. $5 H$ ). The finding that abducens motoneurons and their neuropil showed a normal synaptic density $21 \mathrm{~d}$ after injury and VEGF application was in good agreement with our physiological data.

\section{The astroglial reaction induced by axotomy is prevented by a single VEGF administration}

GFAP immunostaining was used to characterize whether VEGF was able to prevent the glial reaction typically found around axotomized motoneurons. This analysis was performed $21 \mathrm{~d}$ after lesion (with or without VEGF delivery). Measurements were done as described above for synaptophysin. Thus, we determined first the percentage of the somatic perimeter of ChAT-identified motoneurons covered by GFAP-profiles in the three situations, i.e., control $(n=68)$, axotomy alone $(n=55)$, and axotomy plus VEGF $(n=83)$. Images revealed a marked increase in GFAP-IR processes surrounding motoneuronal cell bodies in the axotomy condition (Fig. $6 B$ ) in comparison to the low GFAP staining around control (Fig. 6A) and VEGF-treated cells (Fig. 6C). The statistical analysis confirmed these observations (one-way ANOVA, $F_{(2,203)}=126.267, p<0.001$; Fig. $6 D)$. Thus, there was a significant increase $(p<0.001)$ in GFAP linear density around axotomized motoneuron somata $(42.37 \pm 1.56 \%)$ with respect to control (18.69 \pm $0.89 \%)$, whereas control and VEGF data $(20.09 \pm 0.96 \%)$ were similar $(p=0.349)$.

Second, measurements of GFAP immunostaining intensity (an index of optical density) at the neuropil level, also revealed an increase in GFAP-IR profiles in the abducens neuropil of axotomized animals (Fig. 6F) in comparison to control (Fig. 6E). In contrast, the appearance of GFAP immunostaining in the abducens nucleus neuropil after VEGF intraventricular delivery (Fig. 6G) resembled that of control (Fig. 6E). We compared the optical density for GFAP in the three situations by using the one-way ANOVA test $\left(F_{(2,517)}=155.835, p<0.001 ; n=220,180\right.$, and 120 for control, axotomy, or axotomy plus VEGF, 

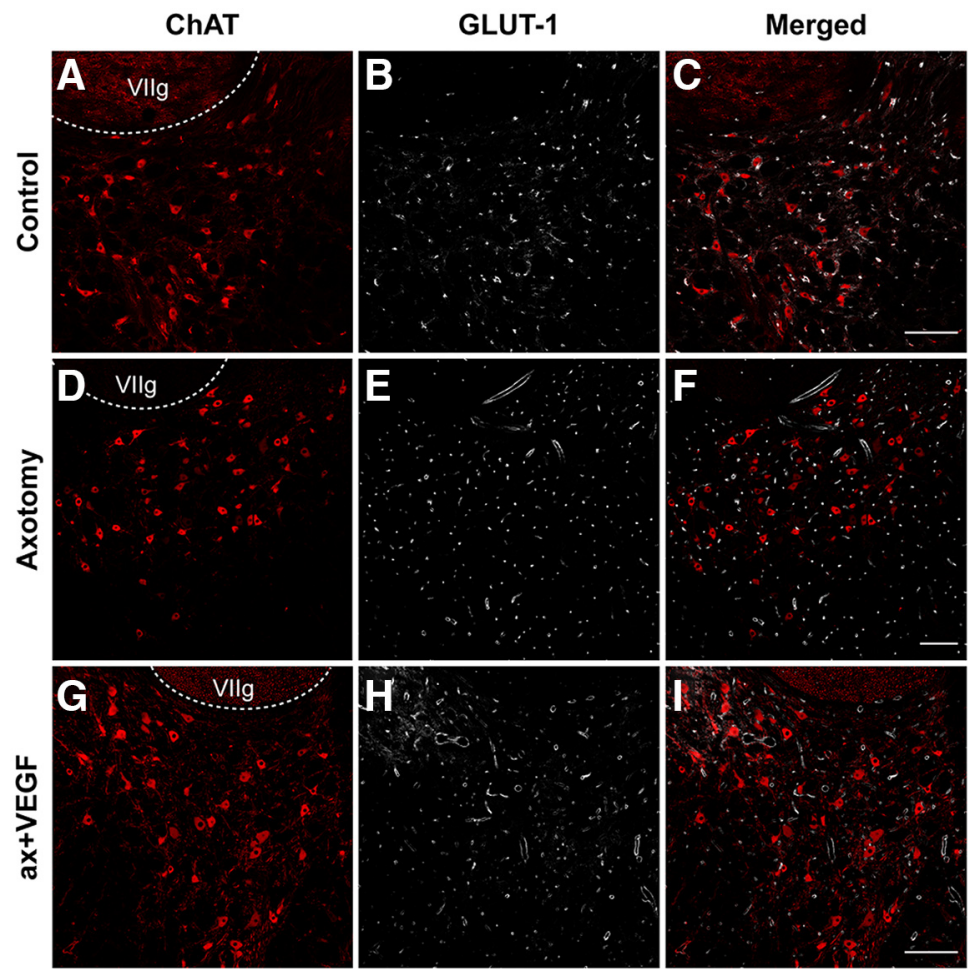

Figure 7. Absence of angiogenic response after VEGF delivery. Confocal images through the abducens nucleus following double immunofluorescence against GLUT-1 (a marker of endothelial cells used to label blood vessels; $\boldsymbol{B}, \boldsymbol{E}, \boldsymbol{H}$ ) and ChAT (a marker of motoneurons; $\boldsymbol{A}, \boldsymbol{D}, \boldsymbol{G})$ in control $(\boldsymbol{A}-\boldsymbol{C})$, axotomy $(\boldsymbol{D}-\boldsymbol{F})$, and after VEGF application $(\boldsymbol{G}-\boldsymbol{I})$. The merged images of GLUT-1 and ChAT immunostaining are shown for each situation in $\boldsymbol{C}, \boldsymbol{F}, \boldsymbol{I}$, respectively. Note the similarity in the density of blood vessels between control, axotomy, and VEGF intraventricular injection. The genu of the facial nerve is indicated (VIlg). Scale bars: $200 \mu \mathrm{m}$ in $\boldsymbol{C}$ (for $\boldsymbol{A}-$ C), $200 \mu \mathrm{m}$ in $\boldsymbol{F}$ (for $\boldsymbol{D}-\boldsymbol{F}$ ), and $200 \mu \mathrm{m}$ in $\boldsymbol{I}$ (for $\boldsymbol{G}-\boldsymbol{I}$ ).

respectively). The statistical comparison revealed a significant $(p<0.001)$ increase in GFAP optical density in the axotomy situation versus control. However, GFAP optical density was similar $(p=0.963)$ between control and VEGF groups. These results indicated that a single administration of VEGF was able to inhibit the astroglial reaction typically found after axotomy.

\section{Intraventricular delivery of VEGF is not followed by angiogenesis in the abducens nucleus}

Since VEGF promotes the formation of new blood vessels when administered in the brain, although in doses higher than the one used here (Manoonkitiwongsa et al., 2004), we investigated whether the injection of $1 \mu \mathrm{g}$ of VEGF into the fourth ventricle induced an angiogenic response in the abducens nucleus. For this purpose, GLUT1 antibody was used as a selective marker of endothelial cells. GLUT-1 was combined in double immunofluorescence with ChAT to label the motoneurons and delimit the boundaries of the abducens nucleus. GLUT- 1 was a good marker of blood vessels, as can be observed in the images of Figure 7 . The appearance of the abducens nucleus in control (Fig. 7A-C), $21 \mathrm{~d}$ after axotomy alone (Fig. $7 D-F$ ), or $21 \mathrm{~d}$ after axotomy plus VEGF supply (Fig. 7G-I) was similar with respect to the density of blood vessels.

A quantification was performed to compare the vasculature in the abducens nucleus between the three situations. We conducted three different vascular measurements. First, vascular density was measured within the limits of the abducens nucleus (delimited by ChAT immunolabeling) using stereological methods (see Materials and Methods). As can be observed in Table 1, there were no significant differences in vascular density between control, axotomy, and axotomy plus VEGF (one-way ANOVA, $\left.F_{(2,26)}=2.466, p=0.105\right)$. Second, the diameter of blood vessels was also measured and again we found absence of significant differences between the three situations (one-way ANOVA, $F_{(2,26)}=2.210, p=0.130$; Table 1). Finally, as a third procedure to measure vasculature we counted the number of blood vessels per $2500 \mu \mathrm{m}^{2}$ in control, axotomy, and axotomy + VEGF. No significant differences were obtained in this parameter between the three situations (one-way ANOVA, $F_{(2,26)}=2.862$, $p=0.075$; Table 1). Therefore, the present findings indicated that the administration of VEGF did not induce any angiogenic response in the abducens nucleus. Moreover, since VEGF was injected into the VIth ventricle, we also measured the vascular network in another brainstem structure, to verify that the result found in the abducens nucleus was general and that indeed VEGF did not induce the growing of blood vessels in the brain. Thus, we also measured the same three vascular parameters as for the abducens nucleus in the medial vestibular nucleus, and in the same three situations (control, axotomy, axotomy + VEGF). For the medial vestibular nucleus, vascular density 
Table 1: Quantification of the vasculature in the abducens nucleus (mean \pm SEM)

\begin{tabular}{lllll}
\hline & $n$ & Control & Axotomy & Axotomy + VEGF \\
Vascular density $(\%)$ & 10 & $1.95 \pm 0.30$ & $2.80 \pm 0.45$ & $1.87 \pm 0.17$ \\
Vessel diameter $(\mu \mathrm{m})$ & 9 & $9.22 \pm 0.48$ & $9.53 \pm 0.47$ & $8.34 \pm 0.27$ \\
No. vessels/2500 $\mu \mathrm{m}^{2}$ & 10 & $4.69 \pm 0.26$ & $4.02 \pm 0.25$ & $4.73 \pm 0.17$ \\
\hline
\end{tabular}

For the analysis of the vasculature in the abducens nucleus in the three situations (control, axotomy, and axotomy + VEGF), we calculated by stereology: (1) vascular density relative to the area of abducens nucleus (in \%); (2) the size of blood vessels by measuring their diameter (in $\mu \mathrm{m}$ ); and (3) the number of vessels per $2500 \mu \mathrm{m}^{2}$. Blood vessels were identified by GLUT-1 immunoreactivity, and the area of the abducens nucleus was delimited by ChAT immunolabeling. In no case, significant differences were obtained between the three situations (ANOVA test; $p=0.105$ for vessel area, $p=0.130$ for vessel diameter, and $p=0.075$ for number of vessels per $2500 \mu \mathrm{m}^{2}$ ).

(one-way ANOVA, $F_{(2,13)}=0.233, p=0.795 ; n=6,5$, and 5 , for control, axotomy, and axotomy + VEGF, respectively), blood vessel diameter (one-way ANOVA, $F_{(2,13)}=$ $0.648, p=0.539 ; n=6,5$, and 5 , for control, axotomy, and axotomy + VEGF, respectively) and number of vessels/ $2500 \mu \mathrm{m}^{2}$ (one-way ANOVA, $F_{(2,13)}=2.159, p=0.155$; $n=6,5$, and 5, for control, axotomy, and axotomy + VEGF, respectively) were similar between control, axotomy, and axotomy plus VEGF. Therefore, the data found in the medial vestibular nucleus reinforced those found at the level of the abducens nucleus, indicating that there was no angiogenic response around abducens motoneurons following the administration of VEGF into the IVth ventricle.

\section{Discussion}

The present work has shown that a single intraventricular administration of VEGF prevents the changes induced by axotomy on the physiological properties and synaptic inputs of abducens motoneurons for a prolonged period of time. Moreover, our data indicate that the beneficial effects of VEGF were not due to its angiogenic activity, but to a direct neurotrophic action of this factor on motoneurons.

\section{A single administration of VEGF produces long-lasting effects in axotomized abducens motoneurons}

Axotomy of abducens motoneurons is characterized by a general decrease in FR that affects both the tonic and the phasic components of the discharge (Delgado-Garcia et al., 1988; Davis-López de Carrizosa et al., 2009, 2010; Calvo et al., 2018). We have delivered a single injection of VEGF into the IVth ventricle of cats in the same surgical session as the axotomy. The administration of VEGF prevented the appearance of the axotomy effects, as shown by the recordings performed from the second day onwards after VEGF injection. A striking finding of the present work was that motoneurons continued firing with normal characteristics up to $50 \mathrm{~d}$ (the maximum time interval studied) after VEGF administration.

This finding contrasts markedly with those obtained previously in our model using other neurotrophic factors, in particular, the neurotrophins brain-derived neurotrophic factor (BDNF), neurotrophin-3 (NT-3), or nerve growth factor (NGF; Davis-López de Carrizosa et al., $2009,2010)$. In those works, the removal of the factor produced the rapid reappearance of the lesion-induced alterations in firing pattern, which indicated that the delivery of BDNF, NT-3, or NGF required continuity over time for the maintenance of their trophic effects. Moreover, these factors produced only partial recovery in the discharge of axotomized abducens motoneurons, in contrast to the complete recovery observed in the present work after VEGF treatment, which points to VEGF as a more powerful neurotrophic factor than neurotrophins for this motoneuronal type.

A possible mechanism to explain the long-term effects of a single administration of VEGF found in the present work might be related to its heparin-binding capability. VEGF has a heparin-binding domain that allows this factor to interact with the heparin-sulfate-rich extracellular matrix, and therefore to remain for a long period of time within the tissue, prolonging its biological activity (Robinson and Stringer, 2001; Tokunaga et al., 2005; Krilleke et al., 2009).

In agreement with our results, previous studies have also shown long-term effects after the single administration of a neurotrophic factor. This has been analyzed extensively in the hemiparkinsonian rat model, induced by the unilateral intrastriatal injection of 6-hydroxydopamine to lesion the nigrostriatal dopaminergic system. A single administration of glial cell line-derived neurotrophic factor (GDNF) to these rats produces behavioral recovery, and increases both the number of substantia nigra neurons and the density of striatum fibers, that last several weeks (12 weeks) after the removal of the factor (Hudson et al., 1995; Kearns and Gash, 1995; Sullivan et al., 1998; Aoi et al., 2000; Yue et al., 2014). Using also the hemiparkinsonian rat model, two novel neurotrophic factors [cerebral dopamine neurotrophic factor (CDNF) and mesencephalic astrocyte-derived neurotrophic factor (MANF)] have also been shown to induce, following their single injection into the striatum, long-lasting (12 weeks) recovery in motor performance and in the number of substantia nigra neurons and striatum fiber density (Lindholm et al., 2007; Voutilainen et al., 2009; Airavaara et al., 2012). Using genetic engineering to turn "on" or "off" BDNF expression, it has also been demonstrated that transient growth factor delivery is sufficient to sustain regenerated axons for prolonged time periods in spinal cord lesion models (Blesch and Tuszynski, 2007). Moreover, studies that have compared single administration with continuous infusion of BDNF or NGF have revealed no difference between both patterns of delivery (Knusel et al., 1996; Chai et al., 1999).

The finding that the discharge of axotomized plus VEGF-treated motoneurons was maintained normal suggests that both electrical membrane properties and synaptic inputs were not affected. Neurotrophic factors are known to regulate voltage-gated ion channels, therefore 
affecting neuronal excitability (Lesser et al., 1997; Blum et al., 2002; Tucker and Fadool, 2002; Mitre et al., 2017). In this regard, it is important to point out that a single pulse of NGF produces long-term neuronal excitability through the induction of sodium channels (Toledo-Aral et al., 1995). Neurotrophic factors are also involved in the formation and stabilization of synapses (Vicario-Abejón et al., 2002), and in the structural and functional changes that operate during synaptic plasticity (McAllister et al., 1999; Poo, 2001; Tyler and Pozzo-Miller, 2001; Elmariah et al., 2004; Kowiański et al., 2018). BDNF plays also an important role in long-term potentiation in the hippocampus (Minichiello, 2009), enhancing the efficacy of synaptic transmission and modulating synaptic structures, including increased number of dendritic spines, changes that are of long duration (Poo, 2001; Castrén, 2013; Park and Poo, 2013).

\section{Synaptic stripping and astroglial reaction in axotomized abducens motoneurons are prevented by a single dose of VEGF}

We also investigated by confocal immunofluorescence the density of synaptic boutons and the astrocytic reaction surrounding motoneurons after both axotomy alone and axotomy + VEGF treatment, to elucidate whether there was a correlation between physiological data and synaptic coverage. This study was performed $21 \mathrm{~d}$ postsurgery.

Following axonal injury, there is a general retrograde response at the cell body level that includes the removal of synapses (the so-called synaptic stripping) from the somata and dendrites of lesioned cells (Svensson et al., 1993; Cullheim and Thams 2007; Thams et al., 2008). Astrocytes and microglia play an important role in this process since they experience hypertrophy with increased level of GFAP and proliferation, respectively (Svensson et al., 1993; Pastor et al., 2000). The profuse glial processes appear interposed between the presynaptic and the postsynaptic membrane, as has been observed at the electron microscopy level, decreasing or suppressing synaptic transmission, a fact that contributes to the loss of input signals and, therefore, to alterations in the discharge pattern (DelgadoGarcia et al., 1988; de la Cruz et al., 2000; Pastor et al., 2000). In line with these arguments, we have observed in axotomized abducens motoneurons a significant increase in GFAP-IR processes and a parallel decrease in synaptophysin-IR synaptic boutons, both around motoneuron somata and in the neuropil. A remarkable finding of the present study was that a single VEGF administration was able to preserve astrocytic GFAP and synaptophysin labeling within normal values, in congruence with the physiological data showing a normal firing pattern in motoneurons, despite their axotomy. In agreement with our data, previous works have also reported the ability of VEGF to decrease the astrocytic reaction that follows different types of injuries in the CNS (Tovar-y-Romo et al., 2007; Zheng et al., 2007; Park et al., 2018; Cabezas et al., 2019).

\section{Intraventricular administration of VEGF does not induce an angiogenic response in the abducens nucleus}

The neuroprotective effects of VEGF have been explained based on two possible mechanisms of action. On the one hand, due to its angiogenic activity, VEGF could provide injured neurons with a better supply of oxygen and nutrients enhancing their chances for recovery. On the other hand, VEGF could act directly as a neurotrophic factor on neurons activating signaling pathways that ultimately restore them to their normal physiological state. To investigate between these two possibilities, we performed a study on the vascular response to VEGF application in the abducens nucleus, at $21 \mathrm{~d}$ postlesion and post-VEGF.

Our data showed that, after VEGF administration, there was no change in the vasculature of the abducens nucleus, as compared with controls. We measured, by stereology, vascular density, vessel diameter and the number of vessels per unit area, using GLUT-1-IR profiles as a marker of blood vessels, within the abducens nucleus (identified by ChAT immunolabeling) in control, axotomized, and VEGF-treated animals. We found that neither axotomy nor VEGF treatment induced any change in these vascular parameters in the abducens nucleus, as compared with the control situation. Moreover, we extended our angiogenic study to other brainstem structures and also found absence of vascular changes due to axotomy or VEGF administration. Other authors have also found no signs of vascular response to VEGF treatment. Thus, the exogenous administration of this factor using osmotic pumps or through the internal carotid artery following different types of lesion does not induce the growing of vascular structures (Manoonkitiwongsa et al., 2004; Tovar-yRomo et al., 2007; Nicoletti et al., 2008). Moreover, it has been demonstrated that the angiogenic activity of VEGF is only promoted by high doses $(60 \mu \mathrm{g} / 7 \mathrm{~d}$ in rats), which, in turn, are not neuroprotective since immature blood vessels formed by angiogenesis are more permeable leading to tissue edema (Manoonkitiwongsa et al., 2004).

In conclusion, and due to the potentiality of VEGF for the treatment of motoneuron disorders, the long-lasting physiological effects of a single dose of VEGF after motoneuron injury found in the present work raise expectations for therapeutic administration, which would avoid the side effects of repetitive or high doses of VEGF.

\section{References}

Airavaara M, Harvey BK, Voutilainen $\mathrm{MH}$, Shen $\mathrm{H}$, Chou J, Lindholm P, Lindahl M, Tuominen RK, Saarma M, Hoffer B, Wang Y (2012) CDNF protects the nigrostriatal dopamine system and promotes recovery after MPTP treatment in mice. Cell Transplant 21:12131223.

Aoi M, Date I, Tomita S, Ohmoto T (2000) The effect of intrastriatal single injection of GDNF on the nigrostriatal dopaminergic system in hemiparkinsonian rats: behavioral and histological studies using two different dosages. Neurosci Res 36:319-325.

Azzouz M, Ralph GS, Storkebaum E, Walmsley LE, Mitrophanous KA, Kingsman SM, Carmeliet P, Mazarakis ND (2004) VEGF delivery with retrogradely transported lentivector prolongs survival in a mouse ALS model. Nature 429:413-417.

Beecher K, Hafner LM, Ekberg J, St John JA, Chehrehasa F (2018) Combined VEGF/PDGF improves olfactory regeneration after unilateral bulbectomy in mice. Neural Regen Res 13:1820-1826.

Blesch A, Tuszynski MH (2007) Transient growth factor delivery sustains regenerated axons after spinal cord injury. J Neurosci 27:10535-10545. 
Blum R, Kafitz KW, Konnerth A (2002) Neurotrophin-evoked depolarization requires the sodium channel $\mathrm{Na}(\mathrm{V}) 1.9$. Nature 419:687693.

Brockington A, Wharton SB, Fernando M, Gelsthorpe $\mathrm{CH}$, Baxter L, Ince PG, Lewis CE, Shaw PJ (2006) Expression of vascular endothelial growth factor and its receptors in the central nervous system in amyotrophic lateral sclerosis. J Neuropathol Exp Neurol 65:26-36.

Büttner-Ennever JA (2006) Neuroanatomy of the oculomotor system. Amsterdam: Elsevier.

Cabezas R, Baez-Jurado E, Hidalgo-Lanussa O, Echeverria V, Ashrad GM, Sahebkar A, Barreto GE (2019) Growth factors and neuroglobin in astrocyte protection against neurodegeneration and oxidative stress. Mol Neurobiol 56:2339-2351.

Calvo PM, de la Cruz RR, Pastor AM (2018) Synaptic loss and firing alterations in axotomized motoneurons are restored by vascular endothelial growth factor (VEGF) and VEGF-B. Exp Neurol 304:6781.

Castrén E (2013) Trophic factors: neurotrophic factors. In: Neuroscience in the 21th century. From basic to clinical (Pfaff DW, ed), pp 1555-1589. New York: Springer.

Chai H, Wu W, So KF, Prevette DM, Oppenheim RW (1999) Longterm effects of a single dose of brain-derived neurotrophic factor on motoneuron survival following spinal root avulsion in the adult rat. Neurosci Lett 274:147-150.

Chi ZL, Adini A, Birsner AE, Bazinet L, Akula JD, D’Amato RJ (2019) PR1P ameliorates neurodegeneration through activation of VEGF signaling pathway and remodeling of the extracellular environment. Neuropharmacology 148:96-106.

Croll SD, Ransohoff RM, Cai N, Zhang Q, Martin FJ, Wei T, Kasselman LJ, Kintner J, Murphy AJ, Yancopoulos GD, Wiegand SJ (2004) VEGF-mediated inflammation precedes angiogenesis in adult brain. Exp Neurol 187:388-402.

Cullheim S, Thams S (2007) The microglial networks of the brain and their role in neuronal network plasticity after lesion. Brain Res Rev 55:89-96.

Davis-López de Carrizosa MA, Tena JJ, Benítez-Temiño B, MoradoDíaz C, Pastor AM, de la Cruz RR (2008) A chronically-implantable device for the controlled delivery of substances, the stimulation and the recording of activity in severed nerves. J Neurosci Methods 167:302-309.

Davis-López de Carrizosa MA, Morado-Díaz CJ, Tena JJ, BenítezTemiño B, Pecero ML, Morcuende SR, de la Cruz RR, Pastor AM (2009) Complementary actions of BDNF and neurotrophin-3 on the firing patterns and synaptic composition of motoneurons. $J$ Neurosci 29:575-587.

Davis-López de Carrizosa MA, Morado-Díaz CJ, Morcuende S, de la Cruz RR, Pastor AM (2010) Nerve growth factor regulates the firing patterns and synaptic composition of motoneurons. J Neurosci 30:8308-8319.

Davis-López de Carrizosa MA, Morado-Díaz CJ, Miller J, de la Cruz RR, Pastor AM (2011) Dual encoding of muscle tension and eye position by abducens motoneurons. J Neurosci 31:2271-2279.

de la Cruz RR, Delgado-García JM, Pastor AM (2000) Discharge characteristics of axotomized abducens internuclear neurons in the adult cat. J Comp Neurol 427:391-404.

Delgado-Garcia JM, del Pozo F, Baker R (1986) Behavior of neurons in the abducens nucleus of the alert cat-I. Motoneurons. Neuroscience 17:929-952.

Delgado-Garcia JM, del Pozo F, Spencer RF, Baker R (1988) Behavior of neurons in the abducens nucleus of the alert cat-III. Axotomized motoneurons. Neuroscience 24:143-160.

Elmariah SB, Crumling MA, Parsons TD, Balice-Gordon RJ (2004) Postsynaptic TrkB-mediated signaling modulates excitatory and inhibitory neurotransmitter receptor clustering at hippocampal synapses. J Neurosci 24:2380-2393.

Escudero M, Delgado-García JM (1988) Behavior of reticular, vestibular and prepositus neurons terminating in the abducens nucleus of the alert cat. Exp Brain Res 71:218-222.
Escudero M, de la Cruz RR, Delgado-García JM (1992) A physiological study of vestibular and prepositus hypoglossi neurones projecting to the abducens nucleus in the alert cat. J Physiol 458:539560.

Ferrara N, Henzel WJ (1989) Pituitary follicular cells secrete a novel heparin-binding growth factor specific for vascular endothelial cells. Biochem Biophys Res Commun 161:851-858.

Fuchs AF, Robinson DA (1966) A method for measuring horizontal and vertical eye movement chronically in the monkey. J Appl Physiol 21:1068-1070.

Fuchs AF, Scudder CA, Kaneko CR (1988) Discharge patterns and recruitment order of identified motoneurons and internuclear neurons in the monkey abducens nucleus. J Neurophysiol 60:18741895.

Geiseler SJ, Morland C (2018) The Janus face of VEGF in stroke. IJMS 19:1362.

Guo H, Zhou H, Lu J, Qu Y, Yu D, Tong Y (2016) Vascular endothelial growth factor: an attractive target in the treatment of hypoxic/ischemic brain injury. Neural Regen Res 11:174-179.

Guo H, Xia D, Liao S, Niu B, Tang J, Hu H, Qian H, Cao B (2019) Vascular endothelial growth factor improves the cognitive decline of Alzheimer's disease via concurrently inducing the expression of ADAM10 and reducing the expression of $\beta$-site APP cleaving enzyme 1 in Tg2576 mice. Neurosci Res 142:49-57.

Hudson J, Granholm AC, Gerhardt GA, Henry MA, Hoffman A, Biddle P, Leela NS, Mackerlova L, Lile JD, Collins F, Hoffer BJ (1995) Glial cell line-derived neurotrophic factor augments midbrain dopaminergic circuits in vivo. Brain Res Bull 36:425-432.

Kearns CM, Gash DM (1995) GDNF protects nigral dopamine neurons against 6-hydroxydopamine in vivo. Brain Res 672:104-111.

Knusel B, Kaplan DR, Hefti F (1996) Intraparenchymal NGF injections in adult and aged rats induce long-lasting Trk tyrosine phosphorylation. Exp Neurol 139:121-130.

Kowiański P, Lietzau G, Czuba E, Was"kow M, Steliga A, Morys" J (2018) BDNF: a key factor with multipotent impact on brain signaling and synaptic plasticity. Cell Mol Neurobiol 38:579-593.

Krilleke D, Ng YS, Shima DT (2009) The heparin-binding domain confers diverse functions of VEGF-A in development and disease: a structure-function study. Biochem Soc Trans 37:1201-1206.

Krum JM, Mani N, Rosenstein JM (2002) Angiogenic and astroglial responses to vascular endothelial growth factor administration in adult rat brain. Neuroscience 110:589-604.

Lange C, Storkebaum E, de Almodóvar CR, Dewerchin M, Carmeliet $P(2016)$ Vascular endothelial growth factor: a neurovascular target in neurological diseases. Nat Rev Neurol 12:439-454.

Lesser SS, Sherwood NT, Lo DC (1997) Neurotrophins differentially regulate voltage-gated ion channels. Mol Cell Neurosci 10:173183.

Lindholm P, Voutilainen MH, Laurén J, Peränen J, Leppänen VM, Andressoo JO, Lindahl M, Janhunen S, Kalkkinen N, Timmusk T, Tuominen RK, Saarma M (2007) Novel neurotrophic factor CDNF protects and rescues midbrain dopamine neurons in vivo. Nature 448:73-77.

Lladó J, Tolosa L, Olmos G (2013) Cellular and molecular mechanisms involved in the neuroprotective effects of VEGF on motoneurons. Front Cell Neurosci 21:181.

Manoonkitiwongsa PS, Schultz RL, McCreery DB, Whitter EF, Lyden PD (2004) Neuroprotection of ischemic brain by vascular endothelial growth factor is critically dependent on proper dosage and may be compromised by angiogenesis. J Cereb Blood Flow Metab 24:693-702.

Matsuzaki H, Tamatani M, Yamaguchi A, Namikawa K, Kiyama H, Vitek MP, Mitsuda N, Tohyama M (2001) Vascular endothelial growth factor rescues hippocampal neurons from glutamate-induced toxicity: signal transduction cascades. FASEB J 15:12181220.

McAllister AK, Katz LC, Lo DC (1999) Neurotrophins and synaptic plasticity. Annu Rev Neurosci 22:295-318.

Minichiello L (2009) TrkB signalling pathways in LTP and learning. Nat Rev Neurosci 10:850-860. 
Mitre M, Mariga A, Chao MV (2017) Neurotrophin signalling: novel insights into mechanisms and pathophysiology. Clin Sci (Lond) 131:13-23.

Morado-Díaz CJ, Matarredona ER, Morcuende S, Talaverón R, Davis-López de Carrizosa MA, de la Cruz RR, Pastor AM (2014) Neural progenitor cell implants in the lesioned medial longitudinal fascicle of adult cats regulate synaptic composition and firing properties of abducens internuclear neurons. J Neurosci 34:70077017.

Nicoletti JN, Shah SK, McCloskey DP, Goodman JH, Elkady A, Atassi H, Hylton D, Rudge JS, Scharfman HE, Croll SD (2008) Vascular endothelial growth factor is up-regulated after status epilepticus and protects against seizure-induced neuronal loss in hippocampus. Neuroscience 151:232-241.

Nicoletti JN, Lenzer J, Salerni EA, Shah SK, Elkady A, Khalid S, Quinteros D, Rotella F, Betancourth D, Croll SD (2010) Vascular endothelial growth factor attenuates status epilepticus-induced behavioral impairments in rats. Epilepsy Behav 19:272-277.

Oosthuyse B, Moons L, Storkebaum E, Beck H, Nuyens D, Brusselmans K, Van Dorpe J, Hellings P, Gorselink M, Heymans S, Theilmeier G, Dewerchin M, Laudenbach V, Vermylen P, Raat H, Acker T, Vleminckx V, Van Den Bosch L, Cashman N, Fujisawa H, et al. (2001) Deletion of the hypoxia-response element in the vascular endothelial growth factor promoter causes motor neuron degeneration. Nat Genet 28:131-138.

Pan Z, Fukuoka S, Karagianni N, Guaiquil VH, Rosenblatt MI (2013) Vascular endothelial growth factor promotes anatomical and functional recovery of injured peripheral nerves in the avascular cornea. FASEB J 27:2756-2767.

Park H, Poo MM (2013) Neurotrophin regulation of neural circuit development and function. Nat Rev Neurosci 14:7-23.

Park MH, Lee JY, Jeong MS, Jang HS, Endo S, Bae JS, Jin HK (2018) The role of Purkinje cell-derived VEGF in cerebellar astrogliosis in Niemann-Pick type C mice. BMB Rep 51:79-84.

Pastor AM, Delgado-García JM, Martínez-Guijarro FJ, López-García C, de la Cruz RR (2000) Response of abducens internuclear neurons to axotomy in the adult cat. J Comp Neurol 427:370-390.

Poo MM (2001) Neurotrophins as synaptic modulators. Nat Rev Neurosci 2:24-32.

Robinson CJ, Stringer SE (2001) The splice variants of vascular endothelial growth factor (VEGF) and their receptors. J Cell Sci 114:853-865.

Robinson DA (1970) Oculomotor unit behavior in the monkey. J Neurophysiol 33:393-404.

Senger DR, Galli SJ, Dvorak AM, Perruzzi CA, Harvey VS, Dvorak HF (1983) Tumor cell secrete a vascular permeability factor that promotes accumulation of ascites fluid. Science 219:983-985.

Storkebaum E, Lambrechts D, Carmeliet P (2004) VEGF: once regarded as a specific angiogenic factor, now implicated in neuroprotection. Bioessays 26:943-954.

Storkebaum E, Lambrechts D, Dewerchin M, Moreno-Murciano MP, Appelmans S, Oh H, Van Damme P, Rutten B, Man WY, De Mol M, Wyns S, Manka D, Vermeulen K, Van Den Bosch L, Mertens N, Schmitz C, Robberecht W, Conway EM, Collen D, Moons L, et al. (2005) Treatment of motoneuron degeneration by intracerebroventricular delivery of VEGF in a rat model of ALS. Nat Neurosci 8:8592.

Sullivan AM, Opacka-Juffry J, Blunt SB (1998) Long-term protection of the rat nigrostriatal dopaminergic system by glial cell line-derived neurotrophic factor against 6-hydroxydopamine in vivo. Eur J Neurosci 10:57-63.

Sun Y, Jin K, Xie L, Childs J, Mao XO, Logvinova A, Greenberg DA (2003) VEGF-induced neuroprotection, neurogenesis, and angiogenesis after focal cerebral ischemia. J Clin Invest 111:18431851.
Svensson M, Eriksson P, Persson JK, Molander C, Arvidsson J, Aldskogius $H$ (1993) The response of central glia to peripheral nerve injury. Brain Res Bull 30:499-506.

Thams S, Oliveira A, Cullheim S (2008) MHC class I expression and synaptic plasticity after nerve lesion. Brain Res Rev 57:265-269.

Tokunaga Y, Yamazaki Y, Morita T (2005) Identification and localization of heparin-binding region of snake venom VEGF and its blocking of VEGF-A165. Pathophysiol Haemost Thromb 34:194-196.

Toledo-Aral JJ, Brehm P, Halegoua S, Mandel G (1995) A single pulse of nerve growth factor triggers long-term neuronal excitability through sodium channel gene induction. Neuron 14:607-611.

Tovar-y-Romo LB, Tapia R (2010) VEGF protects spinal motor neurons against chronic excitotoxic degeneration in vivo by activation of PI3-K pathway and inhibition of p38MAPK. J Neurochem 115:1090-1101.

Tovar-y-Romo LB, Zepeda A, Tapia R (2007) Vascular endothelial growth factor prevents paralysis and motoneuron death in a rat model of excitotoxic spinal cord neurodegeneration. J Neuropathol Exp Neurol 66:913-922.

Tucker K, Fadool DA (2002) Neurotrophin modulation of voltagegated potassium channels in rat through TrkB receptors is time and sensory experience dependent. J Physiol 542:413-429.

Tyler WJ, Pozzo-Miller LD (2001) BDNF enhances quantal neurotransmitter release and increases the number of docked vesicles at the active zones of hippocampal excitatory synapses. J Neurosci 21:4249-4258.

Vicario-Abejón C, Owens D, McKay R, Segal M (2002) Role of neurotrophins in central synapse formation and stabilization. Nat Rev Neurosci 3:965-974.

Voutilainen MH, Bäck S, Pörsti E, Toppinen L, Lindgren L, Lindholm P, Peränen J, Saarma M, Tuominen RK (2009) Mesencephalic astrocyte-derived neurotrophic factor is neurorestorative in rat model of Parkinson's disease. J Neurosci 29:9651-9659.

Wang L, Wang F, Liu S, Yang X, Yang J, Ming D (2018) VEGF attenuates 2-VO induced cognitive impairment and neuronal injury associated with the activation of PI3K/Akt and Notch1 pathway. Exp Gerontol 102:93-100.

Wang Y, Mao XO, Xie L, Banwait S, Marti HH, Greenberg DA, Jin K (2007) Vascular endothelial growth factor overexpression delays neurodegeneration and prolongs survival in amyotrophic lateral sclerosis mice. J Neurosci 27:304-307.

Wang Y, Duan W, Wang W, Di W, Liu Y, Liu Y, Li Z, Hu H, Lin H, Cui C, Li D, Dong H, Li C (2016) scAAV9-VEGF prolongs the survival of transgenic ALS mice by promoting activation of M2 microglia and the PI3K/Akt pathway. Brain Res 1648:1-10.

Yancopoulos GD, Davis S, Gale NW, Rudge JS, Wiegand SJ, Holash $J$ (2000) Vascular-specific growth factors and blood vessel formation. Nature 407:242-248.

Yue X, Hariri DJ, Caballero B, Zhang S, Bartlett MJ, Kaut O, Mount DW, Wüllner U, Sherman SJ, Falk T (2014) Comparative study of the neurotrophic effects elicited by VEGF-B and GDNF in preclinical in vivo models of Parkinson's disease. Neuroscience 258:385400.

Zachary I (2005) Neuroprotective role of vascular endothelial growth factor: signalling mechanisms, biological function, and therapeutic potential. Neurosignals 14:207-221.

Zeng Y, Han H, Tang B, Chen J, Mao D, Xiong M (2018) Transplantation of recombinant vascular endothelial growth factor (VEGF)189-neural stem cells downregulates transient receptor potential vanilloid 1 (TRPV1) and improves motor outcome in spinal cord injury. Med Sci Monit 24:1089-1096.

Zheng C, Sköld MK, Li J, Nennesmo I, Fadeel B, Henter JI (2007) VEGF reduces astrogliosis and preserves neuromuscular junctions in ALS transgenic mice. Biochem Biophys Res Commun 363:989993. 